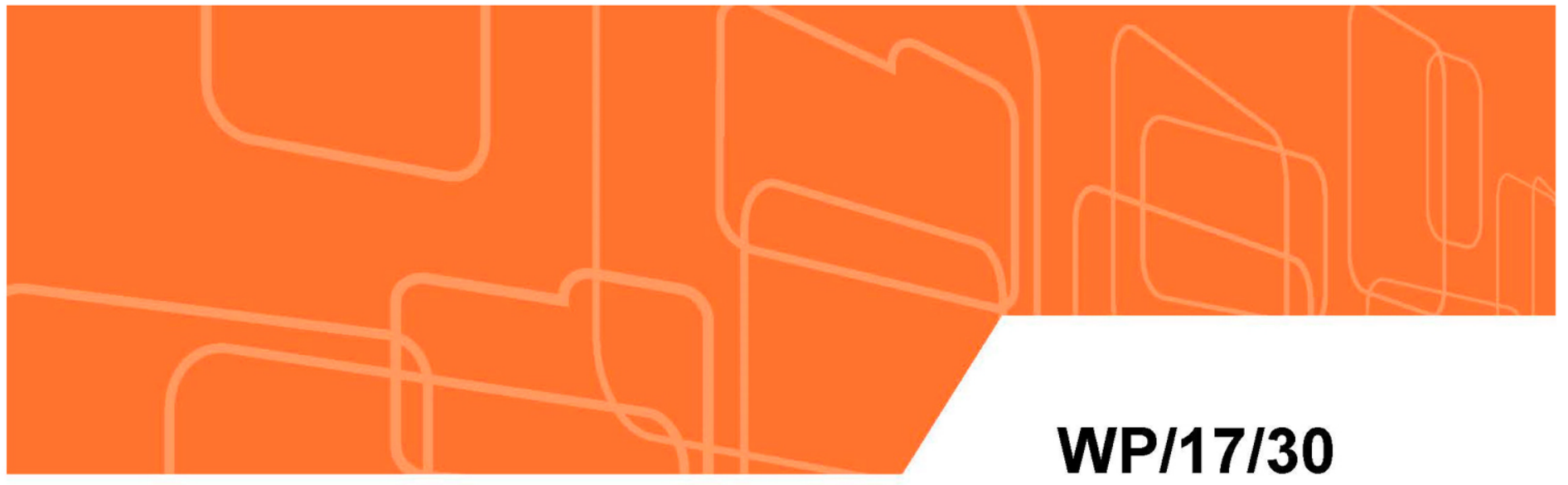

IMF Working Paper

\title{
Assessing the Fragility of Global Trade: The Impact of Localized Supply Shocks Using Network Analysis
}

by Yevgeniya Korniyenko, Magali Pinat, and Brian Dew

IMF Working Papers describe research in progress by the author(s) and are published to elicit comments and to encourage debate. The views expressed in IMF Working Papers are those of the author(s) and do not necessarily represent the views of the IMF, its Executive Board, or IMF management. 


\section{WP/17/30}

\section{IMF Working Paper}

\section{Assessing the Fragility of Global Trade: The Impact of Localized Supply Shocks Using Network Analysis}

IMF Working Papers describe research in progress by the author(s) and are published to elicit comments and to encourage debate. The views expressed in IMF Working Papers are those of the author(s) and do not necessarily represent the views of the IMF, its Executive Board, or IMF management.

$$
\text { I N T ER N A T I O N A L M O N E T A R Y F U N D }
$$




\title{
IMF Working Paper
}

Strategy, Policy, and Review Department

Assessing the Fragility of Global Trade:

The Impact of Localized Supply Shocks Using Network Analysis

Prepared by Yevgeniya Korniyenko, Magali Pinat, and

Brian Dew ${ }^{1}$

Authorized for distribution by Vikram Haksar

February 2017

\begin{abstract}
IMF Working Papers describe research in progress by the author(s) and are published to elicit comments and to encourage debate. The views expressed in IMF Working Papers are those of the author(s) and do not necessarily represent the views of the IMF, its Executive Board, or IMF management.
\end{abstract}

\begin{abstract}
Anecdotal evidence suggests the existence of specific choke points in the global trade network revealed especially after natural disasters (e.g. hard drive components and Thailand flooding, Japanese auto components post-Fukushima, etc.). Using a highly disaggregated international trade database we assess the spillover effects of supply shocks from the import of specific goods. Our goal is to identify inherent vulnerabilities arising from the composition of a country's import basket and to propose effective mitigation policies. First, using network analysis tools we develop a methodology for evaluating and ranking the supply fragility of individual traded goods. Next, we create a country-level measure to determine each country's supply shock vulnerability based on the composition of their individual import baskets. This measure evaluates the potential negative supply shock spillovers from the import of each good.
\end{abstract}

JEL Classification Numbers: C38, F14, F10, F42, D85.

Keywords: international trade, supply shocks, spillovers, network analysis.

Author’s E-Mail Address: ykorniyenko@imf.org; mpinat@imf.org; brian.dew@ american.edu

\footnotetext{
${ }^{1}$ The authors would like to thank Vikram Haksar, Tamim Bayoumi, Murtaza Husain Syed, Camelia Minoiu, Christian Henn, Tito Cordella, Tatiana Didier, Lionel Fontagné, Luca de Benedictis, Raja Kali, participants of the IMF SPR seminar, the XXXVI Sunbelt Conference, the GSIE seminar, and the $5^{\text {th }}$ CIRANO Workshop for suggestions and comments. The views expressed here are those of the authors and not necessarily those of the IMF. All errors and omissions are our own.
} 


\section{$\underline{\text { Contents }}$}

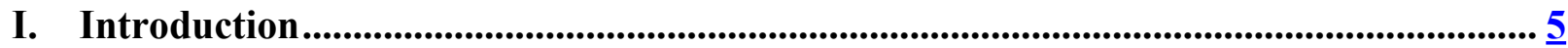

II. Suppply Shocks and Their Consequences for Global Trade: A Review of the

Literature ......................................................................................................................................... 6

III. Empirical Methodology ................................................................................................................

1. The three components of product fragility ............................................................ $\frac{8}{8}$

A. Presence of central players ...............................................................................

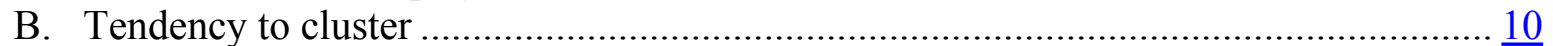

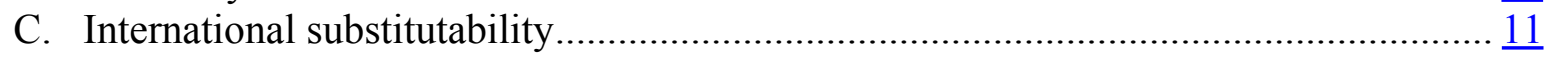

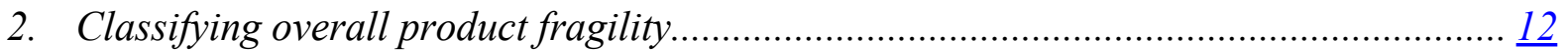

IV. Results and Analysis ............................................................................................................. 12

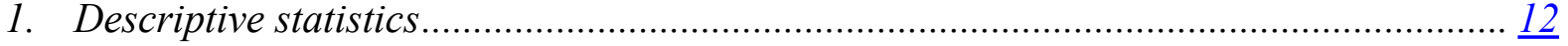

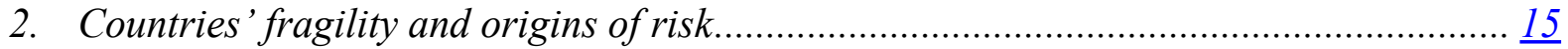

V. Validation of the Methodology ................................................................................................. 18

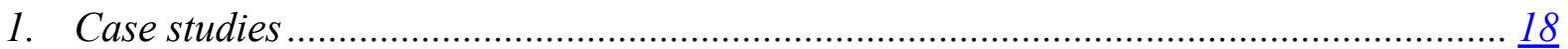

A. 2011 Japanese earthquake and nuclear disaster ……………………....................... $\frac{18}{20}$

B. 2011 Thailand Floods.............................................................................................. 20

2. Cross-country past event validity of the index........................................................... 21

VI. Conclusion and Potential Applications .................................................................................... 24

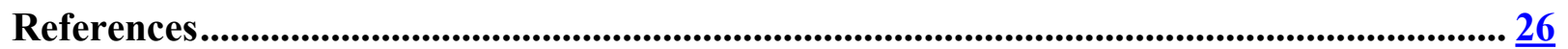

Annex I. Technical details on the definition of components and the overall product fragility measure ................................................................................................................................ 28

Annex II. Descriptive statistics ............................................................................................ 32

Annex III. Fragility maps over time ............................................................................................ $\underline{\mathbf{3 6}}$

Annex IV. Robustness check ...................................................................................................... $\frac{38}{10}$

\section{Figures:}

Fig. 1. Detection of the Presence of Central Players Using Network Analysis ....................................................... 10

Fig. 2. Detection of the Tendency to Cluster Using Network Analysis...............................................................

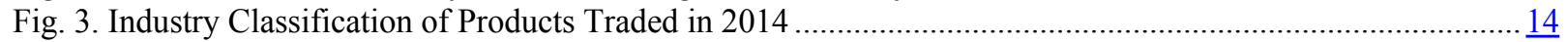

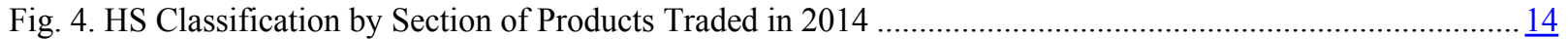

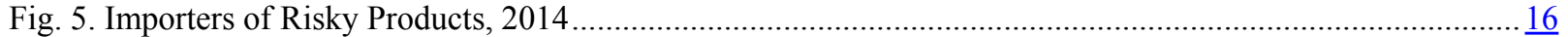

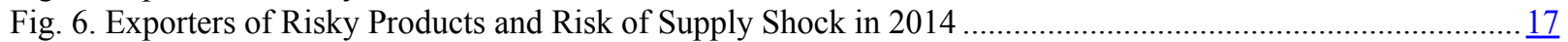

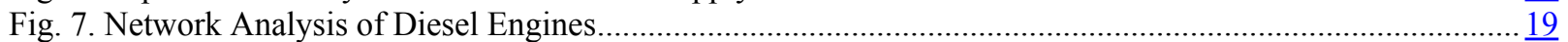

Fig. 8. Macroeconomic Spillovers of Importing Risky Products from Japan.......................................................... $\underline{22}$ 


\section{Tables:}

Table 1. Top 10 Risky Import Products by their Value in Trade ….................................................................13

Table 2. Selected Risky Products Exported by Japan in 2010 ....................................................................... 18

Table 3. Selected Risky Products Exported by Thailand in 2010 ...................................................................

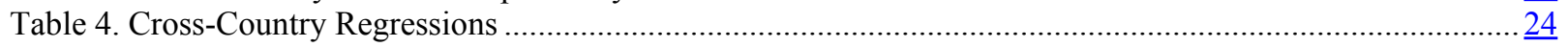




\section{INTRODUCTION}

The IMF review of the role of trade (2015) identifies gaps in the current understanding of trade spillovers to the domestic economy: "The spillovers of trade examined are mostly macroeconomic and on the demand side (...). Supply-side shocks and their welfare effects could be studied." The examination of global trade networks helps to fill this gap by explaining how localized supply shocks can be transmitted to other countries through trade and how these shocks can generate additional domestic disturbance for importer countries. Our methodology seeks to identify and measure supply shock spillover potential arising from fragility in the trade networks of individual goods.

Network analysis provides the foundation for our novel approach to studying supply shock risks in the highly interconnected global trade system. Network analysis of international trade allows exploration of the consequences of potential shocks that is not possible with either classical trade theory analysis at a country level, or bilateral analysis, such as gravity models. New evidence ${ }^{2}$ finds that highly interconnected countries and industries are more vulnerable to economic shocks. When a shock hits, countries with the most connected industries (or with industries heavily involved in the global value chain) are more likely to experience disruptions in production, in particular without concerted government efforts. At the same time, highly interconnected countries that produce easily substitutable goods are better positioned to withstand disruptions in trade ${ }^{3}$.

We assess the sensitivity of import baskets to potential supply shocks ${ }^{4}$ based on individual characteristics of the imported goods using network analysis tools. In this paper, we develop a methodology to evaluate riskiness, and apply it to 3578 product categories. In contrast to existing assessments of vulnerabilities and risks in global trade based on individual product characteristics (quality, cyclicality, complexity, etc.), our methodology breaks new ground by examining the network properties of individual goods. In particular, it underscores the riskiness arising from the presence of central players in the network of a product, from the tendency to cluster, as well as from low international substitutability.

The methodology identifies the most vulnerable products in global trade and tracking top exporters and importers of these products. This methodology also allows the benchmarking of potential import basket vulnerabilities against different countries, country groups, and across regions, and provides a new dataset for cross-country analysis.

The paper proceeds as follows: section II provides a review of the literature on localized supply shocks and their consequences for global trade, and on trade and network analysis. Section III sets the analytical framework, describes the three components of product vulnerability, and discusses the method of classifying a product's overall fragility. Section IV describes and analyzes

\footnotetext{
${ }^{2}$ IMF 2013, Acemoglu et al. 2015; Contreras and Fagiolo 2014.

${ }^{3}$ OECD 2013; UNCTAD 2013 ; de la Torre et al. 2015.

${ }^{4}$ At the moment, we conduct our analysis of localized supply shocks assuming constant demand. While it is a suitable assumption, it is not always realistic. During the global financial crisis, there were a number of examples (see Baldwin (2009), Bems (2010), Freund (2009), WB Global Economic Prospects, Jan 2015) of exporters and importers facing collapse in external and domestic demand who had to adjust their trade flows accordingly. This might complicate the analysis of supply-shocks propagation, as both demand and supply adjust simultaneously.
} 
the results. Section V provides a validation of the methodology based on two case studies and a cross-country analysis. Potential applications and extensions of the research are discussed, and concluding remarks are presented, in section VI.

\section{SUPPLY SHOCKS AND THEIR CONSEQUENCES FOR GLOBAL TRADE: A REVIEW OF THE LITERATURE}

This paper contributes to the literature on international trade and networks. Recent research suggests that microeconomic shocks may be useful for explaining aggregate volatility. Analogously to Carvalho (2014), our idea is that the structure of a production network is key in explaining whether and how microeconomic shocks propagate throughout the economy and impact output ${ }^{5,6}$. Understanding the trade network structure can better explain the origins of aggregate fluctuations and how to prepare for and recover from adverse shocks that disrupt production. We study network characteristics of individual products to identify critical goods that can expose a country to a supply shock from abroad. Our results suggest that the transmission of various types of supply shocks through economic networks and industry interlinkages could have first-order implications for the macroeconomy.

First, our work refers to the consequences of a temporary disruption of inputs for the importing countries. Nguyen and Schaur (2012) find that firms that import goods channel foreign input prices volatility to the domestic market. Bergin et al. (2011) show that offshoring industries in Mexico experience fluctuations in employment that are twice as volatile as the corresponding industries in the U.S ${ }^{7}$. The development of Global Value Chains (GVCs) in the last two decades is key in understanding the consequences of supply shocks in an interconnected world. Carvalho, Nirei, and Saito (2014) examine firm level data before and after the 2011 Great East Japan Earthquake to quantify the spillover effect of exogenous shocks through the supply chain. Firms that were indirectly linked, even with two or three degrees of separation, were found to be affected, establishing that supply-chain linkages constitute a powerful transmission mechanism of otherwise localized shocks. The recent contributions of di Giovanni and Levchenko (2010) and Johnson (2014) show that comovement across countries is potentially the result of the international transmission of shocks through vertical linkages and input-output networks. We aim to go deeper in the understanding of why imports of specific goods from certain trading partners might be at the origin of volatility.

\footnotetext{
${ }^{5}$ Shocks that affect a particular firm or technology along the chain.

${ }^{6}$ Similarly, Acemoglu, Carvalho, Ozdaglar, and Tahbaz-Salehi (2012) argue that in the presence of intersectoral I-O linkages, microeconomic idiosyncratic shocks propagate through a network with higher-order interconnections and cause "cascade effects" to the aggregate economy. The network's structure determines the rate at which the volatility decays. Acemoglu et al. (2015) find that the network-based propagation is larger than the direct effects of the shocks.

${ }^{7}$ In the macroeconomic literature, evidence on the relationship between trade and macro volatility is mixed: some studies, most notably Easterly, Islam, and Stiglitz (2000), and Kose, Prasad, and Terrones (2003) argue that trade openness increases volatility, while others, including Haddad, Lim and Saborowski (2010), Cavallo (2008), and Bejan (2006) show that trade openness decreases volatility. Di Giovanni and Levchenko (2008) exploit variation across countries and across sectors, concluding that trade openness leads to higher volatility of output. This result is similar to Newbery and Stiglitz (1984), who showed that in an open economy, an industry is more vulnerable to world supply and demand shocks.
} 
Our work next refers to literature on how trade is adversely affected by temporary negative supply shocks. A natural disaster such as a hurricane or earthquake, an armed conflict, or political turmoil can temporarily create negative supply shocks due to destroyed production facilities, disruptions in transportation, or reduced human capital. Delays to trade can additionally transmit negative supply shock effects ${ }^{8}$. Oh and Reuveny (2009) find a large and persistent impact of climatic natural disasters on trade, national income, and global economic welfare ${ }^{9}$. Besedes and Murshid (2014) examine the eruption of the Icelandic volcano, Eyjafjallajökull, and find that it negatively impacted exports from the affected countries to the U.S. and Japan. At the same time, Escaith et al. (2011) found that the effect of the earthquake in Japan in 2011 on global trade was relatively small and short-lived, despite the devastation in Japan ${ }^{10}$. In the same vein, conflicts and wars may reduce trade flows by raising costs to private agents of engaging in international trade and investment (Long, 2008; Blomberg and Hess, 2006). Martin, Thoenig and Mayer (2008) findings suggest that a year after a conflict a country's trade is reduced by 25 percent relative to its trade in the absence of a conflict. Glick and Taylor (2010) study the effects of war on bilateral trade with available data extending back to 1870 and find that in war losses to neutral nations are of the same order of magnitude as losses to belligerents. Similarly, a number of empirical studies find an impact of political instability on individual sectors. For example, Muhammad et al. (2011) find evidence of a structural change in the import growth rate for Kenyan roses to the EU, after the 2007/08 post-election violence and political instability in Kenya, which is approximately equivalent to an $18.6 \%$ tariff. This paper aims to find a channel through which localized temporary supply shocks spillover to the global economy.

Lastly, the novelty of our work is in the use of network analysis tools to assess the fragility of global trade. Our approach based on seminal work of Newman (2005) that outlines network analysis tools and techniques including the clustering coefficient and Jackson (2010) who provides a useful guide to representing and measuring network structures and their implications. Recently network analysis tools have been used to analyze global trade. For example, De Benedictis, Nenci, Santoni, Tajoli, and Vicarelli (2014) use the BACI-CEPII database to identify various measures of local and global centrality at a product level. Nevertheless, and to the best of our knowledge, no paper is assessing the systemic risk of the country import basket using network analysis tools and detailed information on traded goods.

\footnotetext{
${ }^{8}$ Djankov, Freund, and Pham (2010) estimate that an additional day spent prior to shipment reduces trade by more than 1 percent. Similarly, Hummels and Schaur (2013) estimate that each day spent in transit costs a firm 0.6-2.1 percent of its shipment's value. Such delays are extremely costly because they impose significant inventory-holding costs, and may destroy perishable goods as well as goods that have seasonal demand.

${ }^{9}$ The impact is particularly pronounced for small developing countries according to Andrade da Silva and Cernat (2012). Similarly, Gassebner et al. (2011), using cross-country analysis, find significant impact of natural disasters on trade, particularly for small countries and autocracies.

${ }^{10}$ For more research on the transmission of natural disasters, such as the 2011 Japanese earthquake, through the global input-output network see Boehm, Flaaen and Pandalai-Nayar (2014), Barrot and Sauvagnat (2014), and Carvalho, Nirei and Saito (2014).
} 


\section{EMPIRICAL METHODOLOGY}

Our research uses detailed BACI bilateral trade data ${ }^{11}$, based on the harmonized system 2002 (HS2002) classification at the 6-digit level, for the period 2003-2014. In total, there are 5224 products and 223 countries and self-governed territories in the database. Final goods and consumption goods, defined using the UN BEC classification, are excluded from the dataset in order to focus exclusively on products that are used by other industries and have the potential for negative spillovers ${ }^{12}$. From 2007 onwards some countries started submitting data using only the HS2007 classification. The HS2002 and HS2007 classifications are merged using correspondence tables, and products with a match from multiple products to multiples products or from one products to multiple products are excluded ${ }^{13}$. Finally, we drop the two products that refer to the crude oil and refined oil category and the products that are not reported in all years of our sample ${ }^{14}$. Our sample shrinks to 3578 products after the cleaning process.

Using this database, we identify three characteristics that contribute to a product's vulnerability to potential supply shocks: (i) the presence of central players; (ii) the tendency to cluster; and (iii) international substitutability. To our knowledge, we are the first to suggest this approach to identify risky products in global trade and to measure the vulnerability of a country import basket to supply shocks based on its' composition. Motivated by this gap in the literature, the main aim of this paper is to construct a measure that is relevant for analyzing inherent vulnerabilities of countries' import baskets using individual product characteristics

\section{The Three Components of Product Fragility}

For each year and product in the sample, we calculate the fragility of the product based on the following three components:

\section{A. Presence of Central Players}

The first characteristic identified as important for the analysis of risky products is the presence of central players in the network of traded goods. The presence of central players has a role in the extent to which microeconomic shocks explain aggregate fluctuations (Gabaix $(2011))^{15}$. Using network analysis measures of centrality we identify products with exporters so

\footnotetext{
${ }^{11}$ Data available at a highly disaggregated level are not split by value-added. This raises the possibility that the network of a product is misrepresented because certain countries add very low value in the process of production (for example, only pieces are assembled). This is a common criticism to work on trade networks, such as the seminal work of Haussman and Hidalgo. Our approach is not totally subject to this criticism. Even if a country is only assembling a good (and not producing it) it is still in the trade network of the product. If the "assembling" country is hit by a temporary shock, it will (at least in the short term) lead to a supply shock for importing countries.

${ }^{12}$ These are 760 consumer goods (including passenger motor cars) and 429 foods and beverage goods mainly for household consumption.

${ }^{13}$ There are 416 products dropped during the process of merging HS2002 and HS2007 classifications; there is not such miscategorization at for the change of classification between HS2007 and HS2012. Two products are dropped due to their classification in miscellaneous products categories 999999 and 9999XX.

${ }^{14}$ This concerns 37 products.

${ }^{15}$ In networks where the largest firms contribute disproportionately to aggregate output, shocks to these firms contribute to aggregate fluctuations. Similarly, Carvalho (2014) uses the Katz-Bonacich measure of centrality, which
} 
integral that a shock to their supply may disrupt importers' production. In network analysis terms, we are looking for a network that is represented by a star shape (Figure 1a), as opposed to a fully connected network (Figure 1b), as star-shaped networks are riskier from the importer point of view.

The standard deviation of weighted outdegree centrality is used to measure the presence of central players ${ }^{16}$. First, the weighted outdegree centrality is calculated for each country in each product network. As detailed in Annex IA, weighted outdegree centrality measures the intensity of a country's exports as a share of the total value of its partners' imports of the product. Countries with many partners and with a high intensity of exports are more likely to generate negative spillovers in case of a negative supply shock. They are often characterized as influential. Starshaped networks are characterized by the presence of $f e w$ central players. The standard deviation of weighted outdegree centrality is calculated for each product network to measure the product's tendency to have few very central exporters; the higher the standard deviation, more likely the star shape and the higher the potential risk ${ }^{17}$.

assigns to each sector a centrality score that is the sum of some baseline centrality level (equal across sectors), and the centrality score of each of its downstream sectors, defined in the same way.

${ }^{16}$ Variants of this measure have been deployed in the sociology literature, notably Bonacich (1972) and Katz (1953), in computer science with Google's PageRank algorithm (Brin and Page, 1998), or in social networks literature within economics (for example, Ballester, Calvo-Armengol, and Zenou, 2006).

${ }^{17}$ Due to data availability, we are not able to use more disaggregated information (such as, for example, HS 10-digit classification or firm level data). A potential concern is the loss of precision in identifying products, as many very similar products would be aggregated to the 6-digit level. There is a possibility that two products at 10-digit disaggregation level would have very different networks (for instance, one being very risky and the other not), and that the aggregation at 6-digit would be misinterpreted. Nevertheless, this would only underestimate the risk associated to the centrality component. Two 10-digit good networks from the same 6-digit category: one star-shaped and the other fully connected, will be fully connected at the 6-digit network. Star-shaped networks that we detect at the 6-digit level effectively only include star-shaped networks at the 10-digit level. We can then affirm that all the categories that are detected as risky contain actually risky products. Case studies reinforce this view. 


\section{Figure 1. Detection of the Presence of Central Players Using Network Analysis}
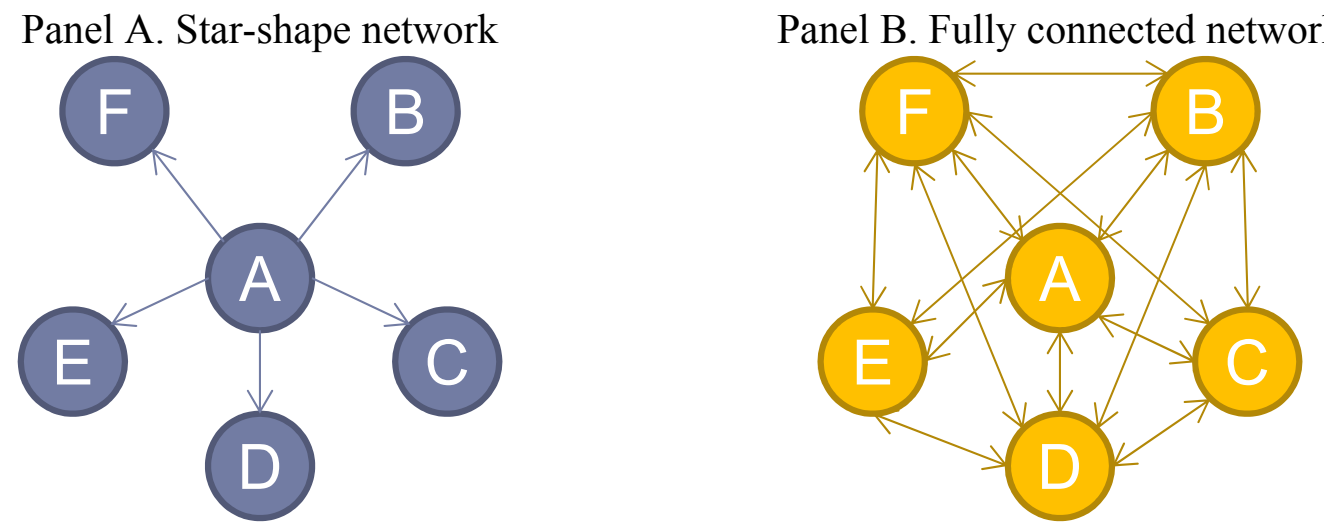

Notes $^{18}$ : Nodes with letters represent countries. The ties that link the nodes show the direction of a trade of a product (either exports/imports, or both). In panel A, the outdegree centrality of node $A$ is equal to one, as country $A$ is exporting to all the countries in the sample. In contrast, the outdegree centrality of countries $B, C, D, E$, and $F$ is equal to zero, as they are exporting to zero countries out of the five possible. The standard deviation of this network is 0.45 . In panel B, all of the countries are trading with all other countries in the network. All countries in this fully connected network have an outdegree centrality of one, so the standard deviation is zero.

\section{B. $\quad$ Tendency to Cluster}

Another characteristic of a product network that increases potential spillover risk is the tendency of groups of countries to cluster - to trade more among each other than with the rest of the world ${ }^{19}$. Figure 2 demonstrates a network with the tendency to cluster. Risk emerges if a cluster is destabilized (for example, after a supply shock to its most central country) as the probability of importers in the cluster finding a new supplier is lower than in product networks where all countries are highly connected (networks with only one cluster).

As detailed in Annex IB, standard algorithms to detect clusters in the network analysis literature are not applicable to trade data. We use two characteristics from cluster analysis to detect products for which countries have tendency to cluster: the weighted average local clustering coefficient and the network diameter. The weighted average local clustering coefficient quantifies how close the partners of a country are to others. In other words, this captures the likelihood of the trade partners of a particular country for a particular good also trading the same good among each other. The higher the clustering coefficient the higher the tendency of countries to cluster.

The weighted average local clustering coefficient is then multiplied by the diameter of the product network. The diameter of a network is the size of the longest direct path-the maximum number of steps that separate the two most distant countries. If a country belonging to a cluster

\footnotetext{
${ }^{18}$ For the sake of clarity, we present an unweighted version of the outdegree measure in this representation. Note that we are using a weighted version in the calculations.

${ }^{19}$ For the relevance and presence of clusters in trade networks, see Fagiolo et al. (2009), Fagiolo, Reyes and Schiavo (2010), Ward, Ahlquist and Rozenas (2013); for the presence of cluster in finance networks, see Hattori and Suda (2007) for the network of international bank exposures, Kubelec and Sá (2010) and Sá (2010) for different asset class and Miniou and Reyes (2011) for the syndicated loans network.
} 
needs to find a new provider, it will be easier to connect to a country in a close cluster (i.e. a cluster already connected to other countries in the clusters).

Figure 2. Detection of the Tendency to Cluster Using Network Analysis

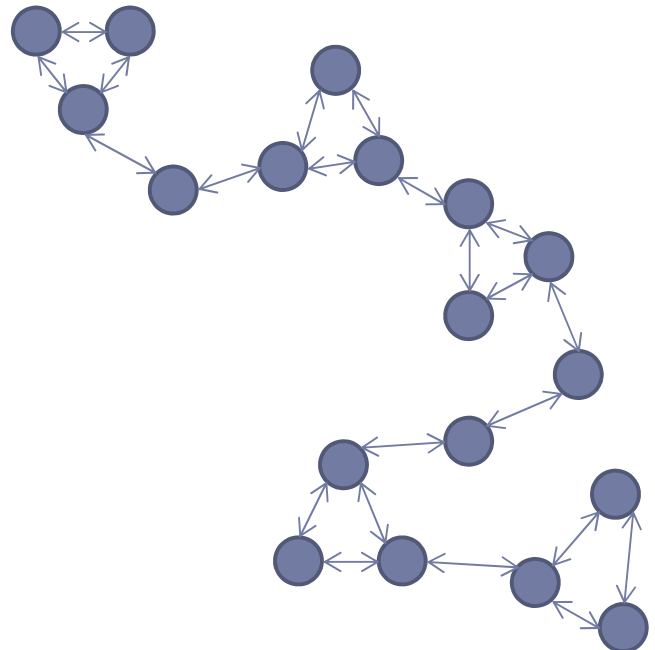

Notes: This network is a typical representation of a tendency to cluster. The weighted average of the local cluster is high (equal to one on a scale going from zero to one) and the diameter is equal to 12. Our measure for tendency to cluster for this particular product is then $1 \times 12=12$ (on a scale going from 0 to the maximum value of the parameter $\left.{ }^{20}\right)$.

\section{International Substitutability}

The final component is the degree of international substitutability of the product. The idea is based on the assumption made by Paul Armington in 1969 that products traded internationally are differentiated by country of origin. As such, when a shock hits major suppliers the extent of spillovers will depend on the availability on international markets of substitutes for any affected goods. If there are no close substitutes in the short run, every user is affected by the disturbances at the source country ${ }^{21}$. Data on the Armington elasticity ${ }^{22}$ of each product is not available, therefore we proxy it with an indicator inspired by Revealed Factor Intensity (RFI) developed by Shirotori, Tumurchudur, and Cadot (2010). We are particularly interested in the level of human capital of each exporter country and its' distribution for each product. In the case of a temporary supply shock, the importing country will look for alternative suppliers with similar characteristics to those

\footnotetext{
${ }^{20}$ The maximum value of the diameter in our case is 11 - the max of the value of diameter of a network for each good between 2003 and 2014.

${ }^{21}$ For example, Tanaka (2012) finds that some Japanese auto parts are less substitutable, which led to the disruptions throughout the global supply chain for the auto industry after the earthquake in Japan in 2011.

22 The estimates vary significantly depending on the method of estimation and data used. Aspalter (2016), Feenstra (2014), Saito (2004) provide some estimates of simple Armington elasticity using both bilateral and multilateral trade data. Additionally, pioneering work by Feenstra, Luck, Obstfeld, and Russ (2014) allows further differentiation between a macro Armington elasticity of substitution between domestic and imported goods and a micro Armington elasticity between different import sources. Their empirical work highlights differences in these micro and macro elasticities. In particular, they find that the macro elasticity is significantly lower than the micro elasticity for up to one-half of the goods considered, relying on both simulation studies and highly disaggregated U.S. data.
} 
who provided the temporally unavailable good. The "wider" the distribution of human capital of exporting countries, the more heterogeneous the available production methods are for a product. This heterogeneity complicates international substitutability, as a country's substitute supplier must comply with its standard of production. Like the presence of influential players and tendency to cluster, low international substitutability adds to the vulnerability of imports ${ }^{23}$.

\section{Classifying Overall Product Fragility}

Identifying which products are risky at 6-digit disaggregation level can help to track importers' vulnerability to supply shocks from abroad and exporters' potential to originate important negative spillovers from natural disasters, political instability, and conflicts. The methodology classifies a product as risky if it scores high in each of the three components described in the previous section. To classify products in different groups we use cluster analysis (the k-median procedure) which is applied to the standardized scores to group the products into risk categories. From the partition exercise we obtain a cluster for which the value of each component is high: this group is defined as risk ${ }^{24,25}$. After categorizing products, the importers and exporters of risky products can be tracked by looking at the risky-product share of total imports or exports in a county's trade basket.

\section{RESULTS AND ANALYSIS}

\section{Descriptive Statistics}

The methodology described in the previous section is applied to the bilateral trade database for each year from 2003-2014 for 223 countries and territories. For each year, products are grouped into four levels of risk (see Annex II Table A.1.; group 4 is considered the riskiest). Over 2003-2014, an average of 655 products are classified in Group 4, and 421 products are consistently classified in Group 4 in each of the fourteen years of the sample (see Annex II Table A.2.). Table 1 presents the ten risky products with the highest global value of imports. Products identified as risky belong mainly to three broad sections: machinery and mechanical appliances (HS codes starting with 84 and 85), and transport equipment (HS codes starting with 87 and 88). Other sections that are overrepresented in Group 4 are pharmaceutical products (30), rubber articles (40), and precision instruments (90).

\footnotetext{
${ }^{23}$ For more details, see Annex I.C.

${ }^{24}$ Note that the partition is not hierarchized, but one group emerges naturally maximizing the value of each of the component.

${ }^{25}$ More details are in Annex I.D.
} 
Table 1. Top 10 Risky Import Products by their Value in Trade

\begin{tabular}{rrll} 
HS2002_6d & \multicolumn{1}{c}{ Product Description } & $\begin{array}{c}\text { Share } \\
\text { Value of } \\
\text { Imports }\end{array}$ \\
\hline 1 & 847170 & Storage units (of auto. data processing machines) & $0.964 \%$ \\
\hline 2 & 880330 & Parts of a eroplanes/helicopters, other than propellers, rotors, under-carri ... & $0.761 \%$ \\
\hline 3 & 870829 & Parts \& accessories of bodies (incl. cabs) of the motor vehicles of $87.01-8 \ldots$ & $0.717 \%$ \\
\hline 4 & 300210 & Antisera \& oth. blood fractions \& modified immunological prods., whether or ... & $0.671 \%$ \\
\hline 5 & 870421 & Motor vehicles for the tpt. of gds. (excl. of 8704.10), with C-I int. comb. ... & $0.573 \%$ \\
\hline 6 & 848180 & Taps, cocks, valves \& sim. appls. for pipes/boiler shells/tanks/vats or the ... & $0.537 \%$ \\
\hline 7 & 850440 & Static converters & $0.523 \%$ \\
\hline 8 & 841191 & Parts of the turbo-jets/turbo-propellers of 8411.11-8411.22 & $0.470 \%$ \\
\hline 9 & 401110 & New pneumatic tyres, of rubber, of a kind used on motor cars (incl. station ... & $0.463 \%$ \\
\hline 10 & 901890 & Instruments \& appls. used in medical/surgical/veterinary sciences, incl. ot ... & $0.455 \%$ \\
\hline$N$
\end{tabular}

Notes: The products shown in the table are consistently classified as risky (cluster Group 4) over 20032014. The ranking is by their value in imports. The top 100 most imported goods constantly classified as the risky over time can be found in Annex Table A.2.

Comparisons of the set of risky products with the full sample by BEC industry classification (Figure 3) and 2-digit HS classification (Figure 4) are presented to assist in summarizing which products are identified as risky. The top bar in Figure 3 shows the total number of products for each industry in 2014 for the full sample of 3578 products, while the bottom bar shows only the products belonging to the risky group. Looking at Figure 3, we observe that processed industrial supply and capital goods are the categories of products most represented in global trade. Interestingly, the comparison between the top and bottom bars shows a different picture of the relative importance. The parts and accessories (P\&A) of transport equipment represent only $3 \%$ of products in the full sample (top bar), but $6 \%$ of the risky products. In contrast, products in the processed industry category are under-represented in the risky group; the category comprises almost $60 \%$ of the full sample but only $37 \%$ of the risky group. 
Figure 3. Industry Classification of Products Traded in 2014

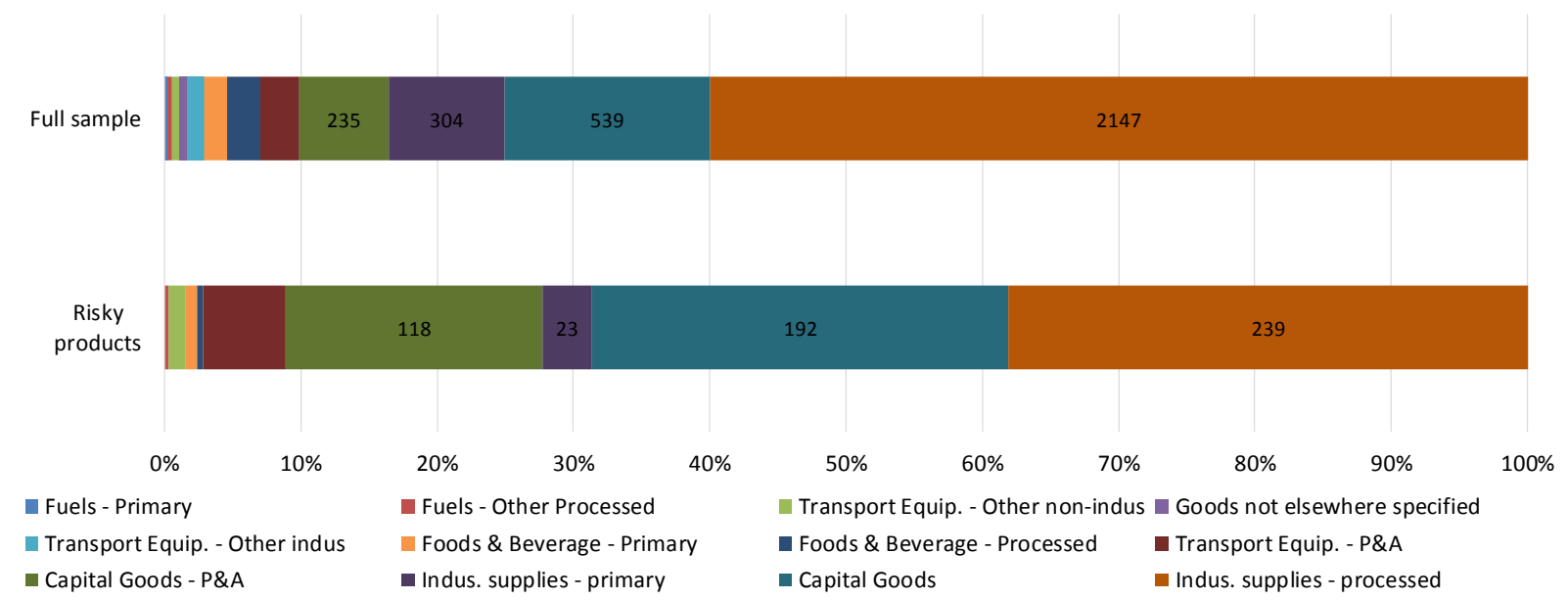

Notes: Classification corresponds to the Broad Economic categories (BEC).

To further analyze what kind of products are defined as risky, the classification by section is compared for the full sample and risky products' group (Figure 4). Similar to Figure 3, the top bar of Figure 4 presents the section composition of goods in the full sample of 3578 products while the bottom bar shows the section composition of only the risky goods. Comparing both panels, we observe the overrepresentation of mechanical appliances and electrical equipment in the risky category. While their share is around $17 \%$ of the full sample, mechanical appliances and electrical equipment comprise more than $38 \%$ of the risky group. Precision and medical equipment is also overrepresented, claiming only $4 \%$ of the full sample but $11 \%$ of the risky products group.

\section{Figure 4. HS Classification by Section of Products Traded in 2014}

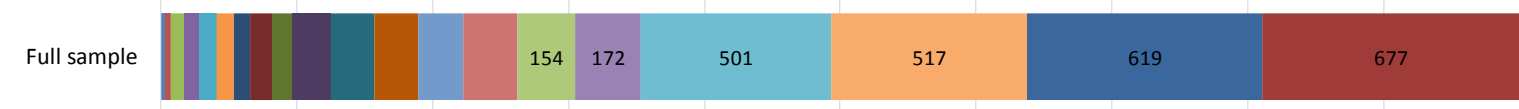

Risky product
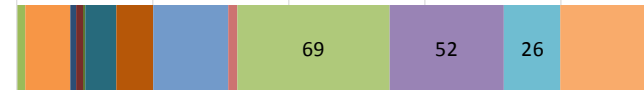

86

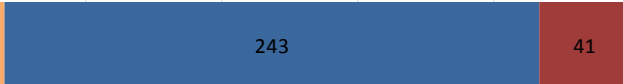

- Footweras and gears

- Precious or semi-precious stones

Woods

- Pulp of wood and paper

- Transport equipment

- Plastics and rubber articles

- Mechanical appliances; electrical equipment arms and ammunition

- Raw hides and skins

- Prepared food and beverages

- Vegetable products

- Mineral products

Textiles

- Products of the chemical or allied industries
- Transformed animal and vegetables products

Miscellaneous manufactured articles

- Animal products

- Stone, cement, ceramic products

- Precision and medical instruments

Base metals and articles of base metal

Notes: Classification corresponds to the HS 2002 2-digit section classification. 


\section{Countries' Fragility and Origins of Risk}

After identifying products with fragile trade networks, we determine which countries are importing and exporting these risky products. The group of products identified as risky comprise on average $25 \%$ of total imports but with a large degree of variation by country (Figure 5 ). A high share of risky products indicates that a country is particularly vulnerable to spillover effects from supply shocks. In 2014, Chad imports the highest share of risky products (43.4\%), followed by the Republic of Congo (39.4\%), Gabon (38.9\%), Equatorial Guinea (37.8\%), and Turkmenistan (37.6\%). Many countries with an above average share of risky imports have notably limited domestic economic diversification. Domestic production, consumption, and often transportation, is dependent upon, and therefore vulnerable to, foreign supply shocks of goods.

A second set of countries import a high share of fragile network products due to their role in international supply chains. These countries import raw materials and intermediate products, add value domestically, and then export the assembled or final product for resale and consumption elsewhere. International supply chain countries with more than $30 \%$ of imports of fragile network products in 2014 include Mexico (37\%), Hungary (36.2\%), Romania (34.2\%), Slovakia (34\%), the Czech Republic (33.9\%), Canada (31.5\%), Germany (30.8\%), and Austria (30.7\%). While a supply chain participating country may not be importing a specific good for its domestic consumption, it is vulnerable to spillovers to its domestic labor supply from supply shocks to these imports. Likewise, a domestic disruption may be transmitted elsewhere through the trade network.

The lowest share of vulnerable products is held by the Bahamas $(7.9 \%)$, followed by Liberia (9.8\%), Somalia (12.7\%), and Cyprus (13\%). Major economies with a low share of fragile network products in their import baskets include India (13.2\%) and Japan (16.6\%), while Korea $(17.6 \%)$ and China $(21.2 \%)$ also have below average vulnerability according to our measure in 2014. The U.S. (24.9\%), France (27.4\%), and U.K. (23.9\%) import baskets are near the mean.

While all countries import fragile products, exporters of such products are very concentrated. Each country's share of world exports of risky products varies dramatically (Figure 6), with most countries exporting virtually none, and the G8 countries exporting $59.7 \%$ of the total. The U.S. exports the largest share (13.1\%) of all fragile network products, followed by Germany $(13 \%)$, Japan $(8.6 \%)$, and China $(7.9 \%)$. The remaining risky product exporters are all middleincome countries or higher. The African continent is represented among risky product exporters only by South Africa, Egypt, Tunisia, and Morocco, which combined export less than one percent of the world's risky products. Importantly, many countries involved in international supply chains and highly specialized production are also therefore exporters of products that exhibit characteristics identified as risky. In 2014, Mexico exports approximately 3\% of the world's risky goods, Korea exports 2.4\%, Austria and Switzerland each export 1.6\%, Malaysia exports 1.5\% and Thailand exports $1.2 \%$.

As shown in our methodology, producers of fragile products can serve as origins of risk if the domestic production of exports is severely constrained. A temporary domestic shock, emerging from political events or from natural disasters, can thereby be transmitted to other countries through the trade of risky products. 

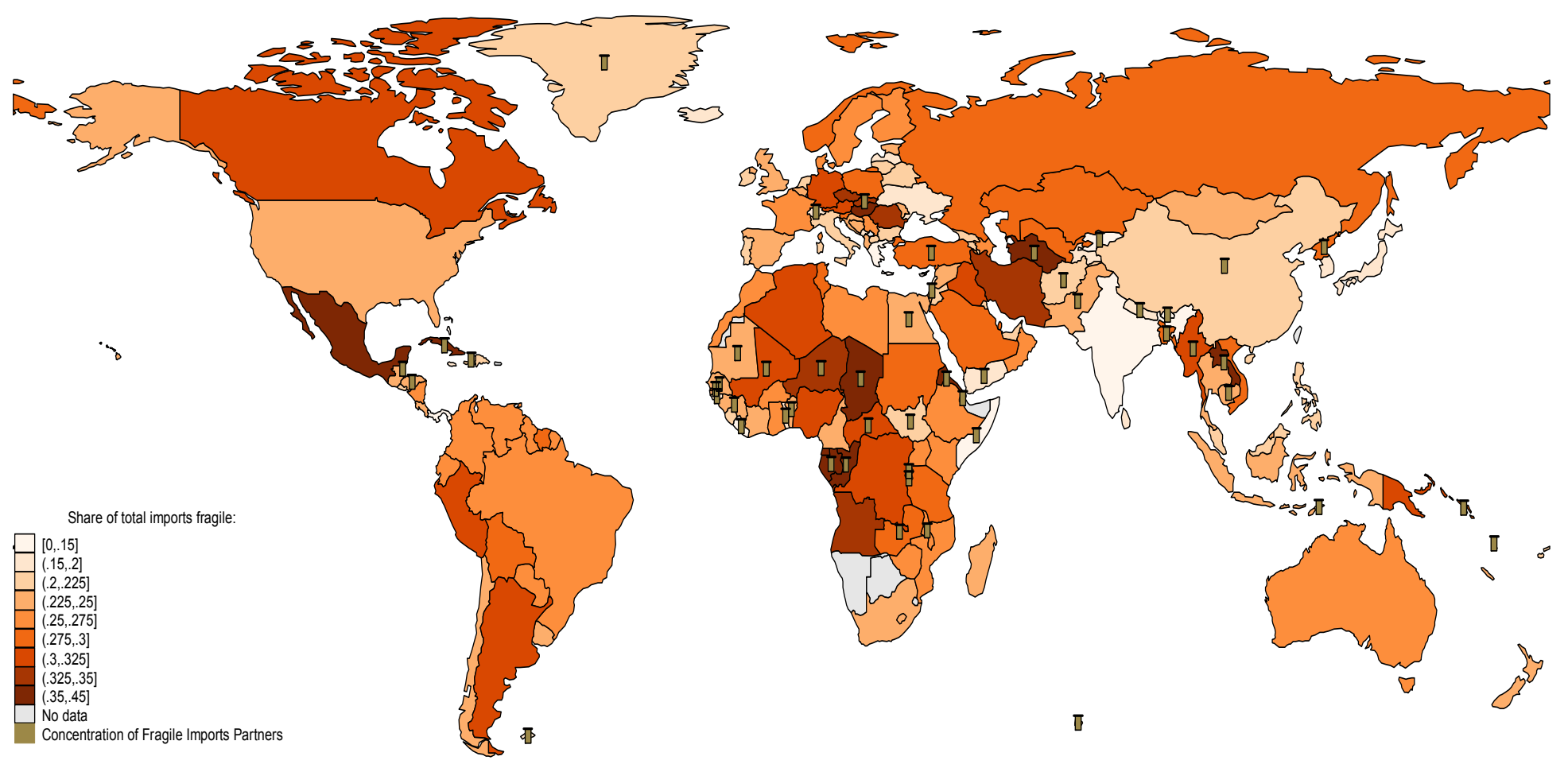

Notes: Latest data available is used for this map, 2014. Source: Authors'calculation based on BACI database. 

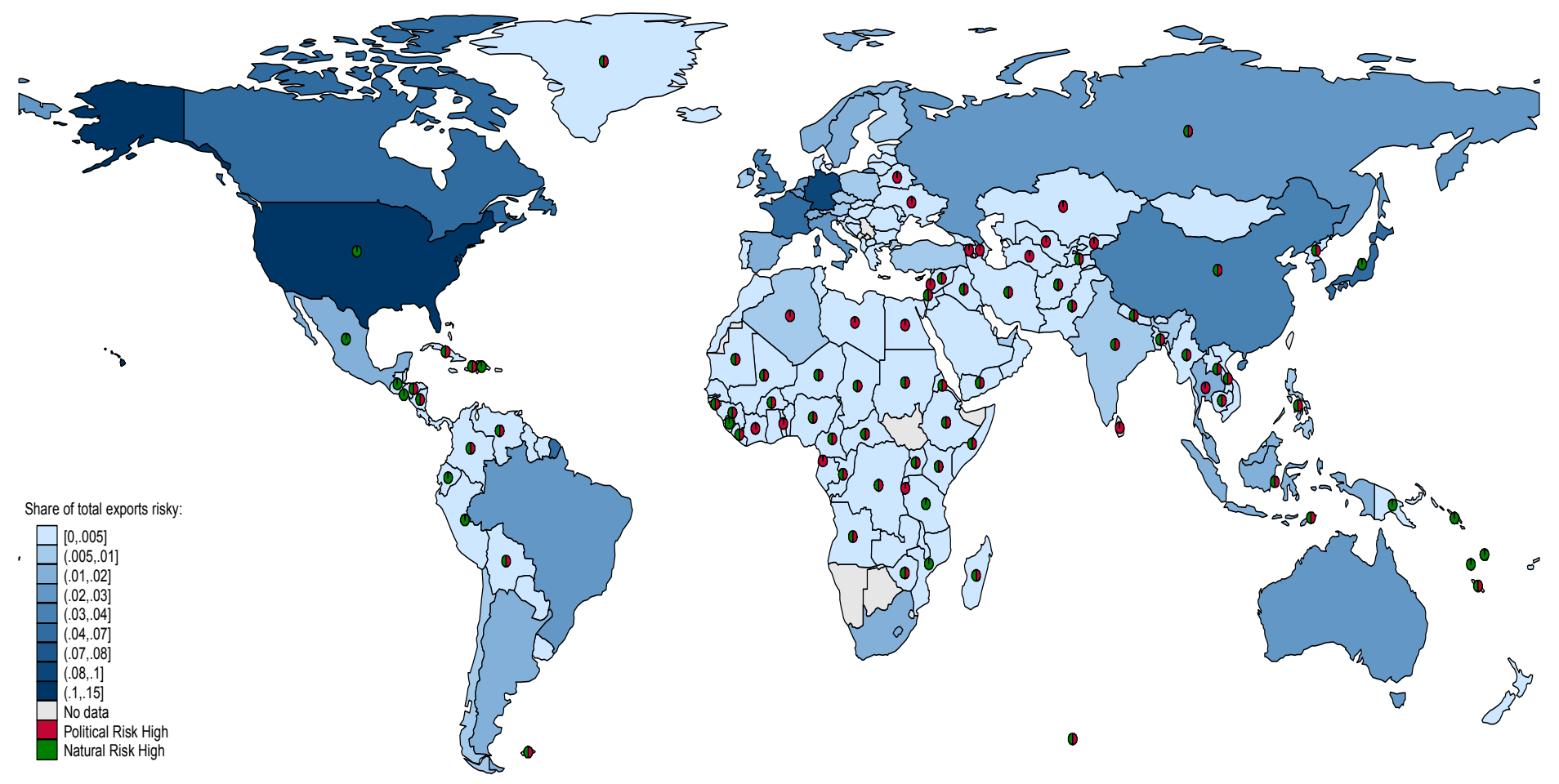

Notes: Latest data available is used for this map: 2014, for the share of imports of fragile products and 2015Q3 for country risks. Risks are displayed only if the information on the data for exports of fragile products is available. The risk is considered high (and displayed on the map) if in the product is in the top third of the sample. Source: authors calculation based on BACI database and Maplecroft data. 


\section{VALIDATION OF THE METHODOLOGY}

Two complimentary approaches are taken to validate the methodology. First, the case of two recent events is studied (the 2011 Japanese earthquake and nuclear disaster and the 2011 Thailand floods). Business literature and media reports identify products that were temporarily unavailable due to the disaster and in some cases note a resultant disruption of production in other countries. Such products are matched in the data to assess the power of prediction of our index one year before a disaster. Next, a cross-country regression analysis estimates the impact on exports (as a proxy of impact on production emphasizing the risk of multiple steps of negative spillovers) of importing risky products from a country suffering a disaster.

\section{Case Studies}

\section{A. 2011 Japanese Earthquake and Nuclear Disaster}

On March 11, 2011, a magnitude 9.0 earthquake struck $70 \mathrm{~km}$ off the eastern coast of Japan. The earthquake and resultant tsunami killed and injured in total more than 21,000 people. Property destruction was enormous with 125,000 buildings totally collapsed and over one million damaged. Manufacturing facilities were damaged or destroyed in three prefectures of the country. The natural disasters were followed by electricity shortages which increased the affected zone and further exacerbated the effect on manufacturing. The economic toll was steep, with 2011 GDP growth figures 2 percentage points below their March 2011 forecast.

In the period following the earthquake, the economic effects of the disasters spread throughout the world through trade and global supply chains, particularly impacting the Asia region $^{26}$. Damage to manufacturing in Japan had been amplified by the riskiness of several key products for which Japan plays a central role in world production. The following products were affected strongly by the disasters: diesel engines, power supply and aluminum capacitors, and LCD screens used in TV sets, notebook computers, smartphones, and tablets (See Table 2).

\section{Table 2. Selected Risky Products Exported by Japan in 2010}

\begin{tabular}{|c|c|c|c|c|c|}
\hline HS2002 6-digit & $\begin{array}{c}\text { Risk } \\
\text { category } \\
\text { in } 2010 \\
\end{array}$ & $\begin{array}{l}\text { Products Description } \\
\text { (sometimes shortened) }\end{array}$ & $\begin{array}{l}\text { z-score } \\
\text { Comp. } 1\end{array}$ & $\begin{array}{l}\text { z-score } \\
\text { Comp. } 2\end{array}$ & $\begin{array}{l}\text { z-score } \\
\text { Comp. } 3\end{array}$ \\
\hline \multicolumn{6}{|c|}{ 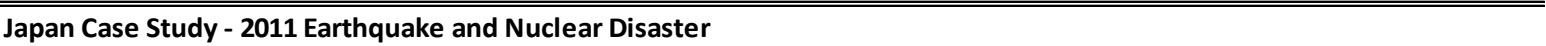 } \\
\hline 840890 & 4 & $\begin{array}{l}\text { Combustion Engines \# Other engines } \\
\text { includes diesel engines }\end{array}$ & 1.39 & 0.95 & 1.68 \\
\hline 853229 & 4 & $\begin{array}{l}\text { Electrical Capacitors \# Other } \\
\text { includes power supply capacitors and aluminium capcacitors }\end{array}$ & 0.89 & 0.74 & 0.32 \\
\hline 901380 & 3 & $\begin{array}{l}\text { LCDs \# Other devices, applicances and instruments } \\
\text { includes } L C D \text { screens in } T V \text { sets, notebook computers, smartphones, and tablets }\end{array}$ & 1.09 & 1.10 & -0.79 \\
\hline
\end{tabular}

Note: Column 1 of Table 2 present the HS2002 6-digit classification of products identified as having disrupted production in other countries after the 2011 disasters. The category of the product is described in columns 3 and the precise description of the good is shown in italics. Column 2 presents the level of risk found with our methodology, 4 being the highest risk category. Out of three products identified, the methodology categorizes two in the highest risk group one year before the event. Columns 4-6 present the standardized value of each component.

\footnotetext{
${ }^{26}$ Harvard Business Review, “The Japan Earthquake Rattles Supply Chains, Too,” March 23, 2011.
} 
Exports of diesel engines by Japan decreased by nearly 20 percent in 2011, as manufacturers were not able to supply parts. A major French automobile manufacturer, for example, in turn delayed the launch of two car models and was eventually forced to source from another supplier. Our work identifies diesel engines as a risky product. This category of product is produced by "central players," has clusters in the trade network (as shown in Figure 7, the Japanese cluster for diesel engines disappears entirely in 2011), are highly systemically relevant, and are not easily substitutable on international markets. The resultant choke point predicted by our methodology proved problematic for importers following the supply shock.

\section{Figure 7. Network Analysis of Diesel Engines}

2010

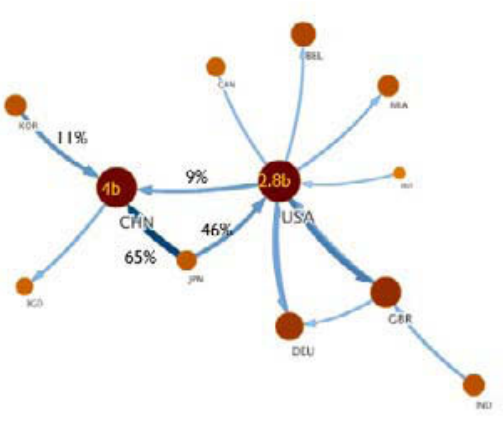

2011

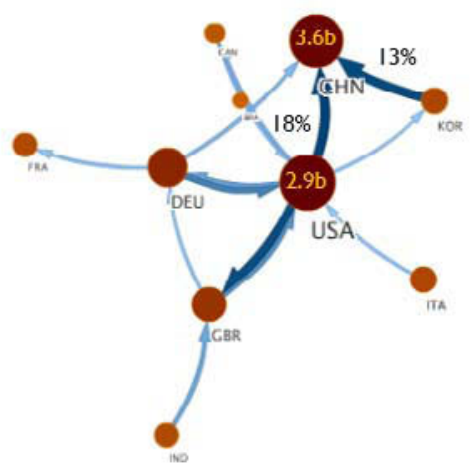

2012

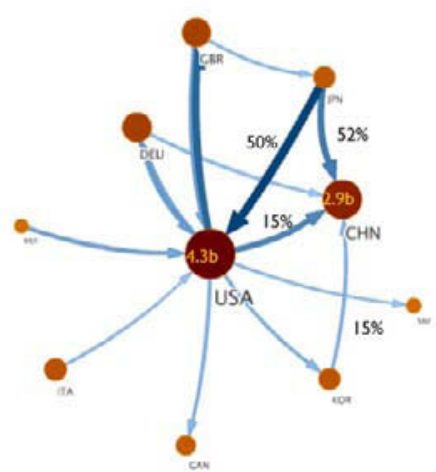

Note: This Figure shows trade networks for product 840890 from the HS2002 classification - a category of diesel engines. We use the community detector of Rosvall and Bergstrom (2008) to show the evolution of the network for this product between 2010 and 2012. Countries are grouped by similarity of their trade matrix and the country with the highest Page Rank centrality is displayed below the node ${ }^{27}$. The bigger the share of trade of the countries in each group, the bigger is the node. Above some links, the share of total imports of the destination country from the country at the origin of the arrow is displayed (e.g., in 2010, the USA imports 46\% of their diesel engines from Japan). On the top of some nodes, the value of imports is displayed (e.g., in 2010, the US had imported 2.8 billion US of diesel engine). The figure shows only the links that reflect the structure of the network. In 2010, Japan is a key player, exporting to both the US and Chinese clusters. In 2011, the year of the Fukushima accident, the Japanese cluster disappears. Korean cluster seems to reinforce exports to China, but not to the US. In 2012, the Japanese cluster is back and the network is more connected than before the earthquake. In 2011, a Belgium and Netherlands simple connection and Iran are omitted from the algorithm-generated graphic for simplicity of presentation.

Small parts can also cause disruption in production and carry outsized trade risks. Capacitors and resistors are critical to global electronics supply chains and Japan is a major producer of these products. Following the earthquake, prices of the tiny inputs increased, and in importer countries, production of various electronics and automotive parts that used the capacitors slowed. Aluminum capacitors are included in a product grouping with very similar risk characteristics to the diesel engines. An additional risky product, the LCD screens used in many

\footnotetext{
${ }^{27}$ The PageRank algorithm defines the centrality as the popularity of a node, i.e. the more central is a country the higher likelihood a trade connection goes through it. Compared to the outdegree centrality we are using in the paper, this algorithm uses recursive equation to compute the centrality.
} 
modern devices, was affected by the disaster and has similar risk characteristics, but was not categorized as high-risk.

\section{B. 2011 Thailand Floods}

The 2011 monsoon season in Thailand brought severe flooding to 65 of Thailand's 77 provinces, causing more than 815 deaths and 45 billion USD of property damage. Triggered by a tropical storm at the end of July, floodwaters spread throughout the northern parts of the country and through the Mekong and Chao Phraya rivers, eventually reaching Bangkok. Efforts made to protect the capital city from the floodwaters were successful to varying degrees.

Industrial estates and manufacturing facilities were badly flooded in many parts of the country, causing production and exports to be adversely affected. Literature on the economic effects of the floods mentions some specific products which had seemingly outsized consequences on global trade and supply chains. Three such products were hard disk drives, semiconductors, and pick-up trucks ${ }^{28}$. All three of these products are listed as risky according to our methodology; two of which display all three of the risky characteristics.

Thailand is the world's second largest producer of hard disk drives, which serve as the "long-term" memory and file storage in desktop and laptop computers, tablets, and mobile devices. When factories which produce these hard drives were flooded, exports decreased, prices increased (almost doubling and remaining elevated for two years), and production of the electronic devices which use these intermediate goods slowed in many countries. Hard disk drives are a risky good according to our methodology, which exhibits particularly high levels of out degree centrality and clustering.

Flooding also damaged the manufacturing equipment used to produce semiconductors and pick-up trucks. Suspension of the production of pick-up trucks in Thailand has economic impact in Japan, whose automotive companies produce in Thailand, and in the countries from which source component orders are suspended. Similarly, suspended semiconductor production in Thailand slowed other countries' production of goods for which semiconductors are an intermediate input. Semiconductors and integrated circuits are valuable exports for which Thailand is a fairly central player, and also register above average in three areas of trade risk (see Table 3 for the correspondence with our methodology).

${ }^{28}$ Reuters, “Thai floods batter global electronics, auto supply chains," October 28, 2011. 
Table 3. Selected Risky Products Exported by Thailand in 2010.

\begin{tabular}{|c|c|c|c|c|c|}
\hline HS2002 6-digit & $\begin{array}{c}\text { Risk } \\
\text { category } \\
\text { in } 2010 \\
\end{array}$ & $\begin{array}{l}\text { Products Description } \\
\text { (sometimes shortened) }\end{array}$ & $\begin{array}{l}\text { z-score } \\
\text { Comp. } 1\end{array}$ & $\begin{array}{l}\text { z-score } \\
\text { Comp. } 2\end{array}$ & $\begin{array}{l}\text { z-score } \\
\text { Comp. } 3\end{array}$ \\
\hline \multicolumn{6}{|c|}{ Thailand Case Study - 2011 Floods } \\
\hline 847170 & 4 & $\begin{array}{l}\text { Computers \# Storage units } \\
\text { includes computer hard disk drives }\end{array}$ & 2.66 & 1.68 & 1.40 \\
\hline 854121 & 4 & $\begin{array}{l}\text { Semiconductor Devices \# with a dissipation rate of less than } 1 \mathrm{~W} \\
\text { includes semiconductors used in microprocessors }\end{array}$ & 0.58 & 1.09 & 1.38 \\
\hline 870421 & 4 & $\begin{array}{l}\text { Delivery Trucks \# g.v.w. not exceeding } 5 \text { tonnes } \\
\text { includes pick up trucks }\end{array}$ & 2.42 & 2.72 & 1.70 \\
\hline
\end{tabular}

Note: Column 1 of Table 3 present the HS2002 6-digit classification of products identified as having disrupted production in other countries after the 2011 event in Thailand. The category of the product is described in column 3 and the precise description of the good is shown in italic. Column 2 presents the level of risk found with our methodology, 4 being the highest risk category. The methodology categorizes all of the products in the highest risk group one year before the event. Columns 4-6 detail the standardized value of each component.

\section{Cross-Country Past Event Validity of the Index}

In this last section we test the validity of the hypothesis that the more a country imports risky goods from a partner suffering a disaster, the more substantial the impact will be on the economy, and particularly to the countries' export flows. To introduce the results of this section, we use the 2011 Japanese earthquake case study and its negative consequences on its trade partners. We show in Figure 8, the correlation between the reliance on risky products from Japan in 2010 and the exports growth in 2011. Figure 8 panel A plots real export growth in 2011 on the $\mathrm{y}$-axis and the share of imports from Japan in 2010 on the $\mathrm{x}$-axis. The relation is slightly negative and non-statistically significant. In panel B, x-axis is replaced by the share of imports of the risky goods from Japan, keeping y-axis unchanged. The relationship is even more negative and significant. 


\section{Figure 8. Macroeconomic Spillovers of Importing Risky Products from Japan}

Panel A. share of imports from Japan and 2011 exports growth

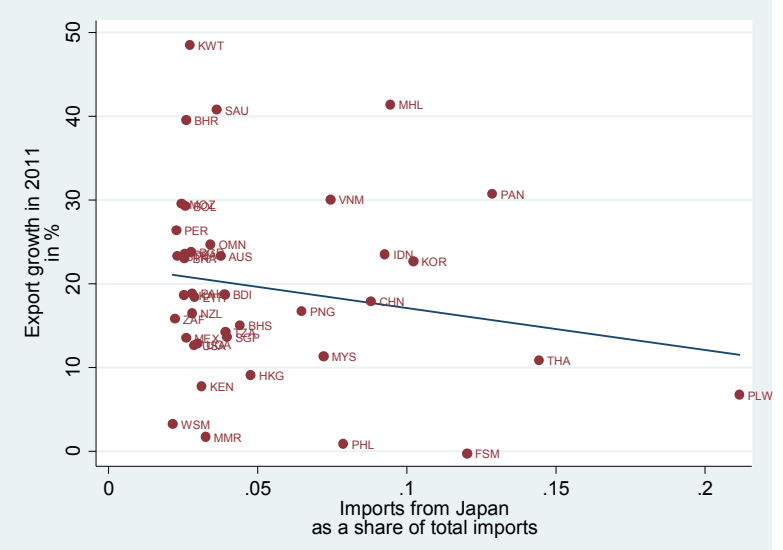

Panel B. share of imports of risky products from Japan and 2011 exports growth

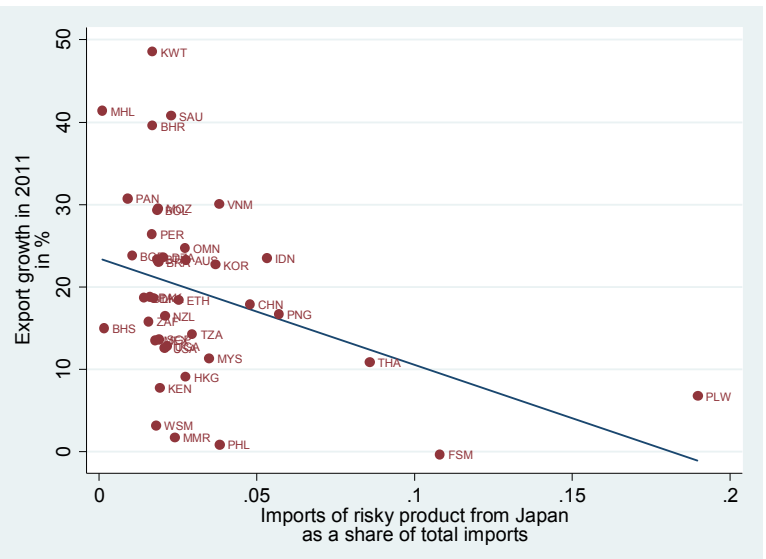

Notes: Equation of the fitted line is $y=-50.4 \beta-22.2^{* * *}$ for panel $A$ and $y=-129.5^{* *} \beta-23.5^{* * *}$ for panel B. Only countries for which Japan represents at least $2 \%$ of the total imports are displayed

Next, using a panel regression setting, the validity of these results for all countries and all available data is tested. We assess whether the measure of import riskiness has an impact on the export growth of a country, when one or more partner(s) country is suffering a localized supply shock in (t-1). More formally, we run a within-group estimation model for the period 2003-2014, at the country-year level:

$$
\hat{X}_{i, t}=\beta_{1} \ln \left(R E E R_{i, t-1}\right)+\beta_{2} X_{i, t-1}+\beta_{3} R M_{i, t-1}+\beta_{4} M I C_{i, t-1}+\beta_{5} R M I C_{i, t-1}+\delta_{i, t}+\varepsilon_{i, t}
$$

where $\widehat{X}_{i, t}$ is the growth of exports' volumes of country $i$ in period $t$.

In the basic setup, we first control for changes in exchange rates using the natural logarithm of the real effective exchange rate (REER). Appreciation of the exchange rate in $t-1$ is negatively associated with export growth in period t. Next, we control for the year fixed effects $\left(\delta_{i, t}\right)$, and define $\varepsilon_{i, t}$ as the error term of the model.

$R M I C_{t-1}$ is the share of total imports of products considered as risky by our methodology in period $t-1$ from countries that suffer a large natural disaster in period $t^{29}$. To assure the validity of our results, we also control for the share of total imports that is risky $\left(R M_{i, t-1}\right)$, and the share of total imports from countries suffering a disaster in $t-1\left(M I C_{i, t-1}\right)$. We argue that importing risky products is not an issue as long as there is no disruption of supply. Also, we do not have a prior on the relationship between importing non-risky products from a country suffering a disaster and its impact on countries' exports.

\footnotetext{
${ }^{29}$ RMIC stands for Risky Imports from Impacted Country
} 
Data on total exports, total imports, and GDP comes from the IMF Balance of Payments Statistics (BOPS) database and are adjusted to constant prices using data obtained from the U.S. Federal Reserve Bank of St. Louis FRED database ${ }^{30}$. REER data is obtained from the World Bank and indexed to 2010. The BACI database is used in the construction of the country-level measure to calculate the share of products traded. Large natural disasters data is constructed based on the EM-DAT database, which collects data on natural disasters and their effects. Natural disasters include among others, hydrological (such as floods), meteorological (such as storms), and geophysical (such as earthquakes). We define a disaster as large by the damage it generates as a share of GDP. Specifically, disasters in the $90^{\text {th }}$ percentile by damage are considered large; there are 112 such events during 2004-2014.

Table 4 presents the results of the within-group estimations. The coefficient associated with the REER, as expected, is negative, but not statistically different from zero; a higher REER (meaning appreciation of the currency) is negatively associated with export growth. The coefficient associated with total exports is negative and statistically significant, supporting a story of convergence in export flows, where the higher the level of exports, the lower the export growth rate. Next, the coefficient on the share of total imports in $t-1$ of goods identified as risky in our methodology from a country suffering a large natural disaster in period $t$ is negative and statistically significant at the $15 \%$ confidence level. A $1 \%$ increase in imports of risky products from a country suffering a natural disaster is associated with a $0.7 \%{ }^{31}$ decrease in exports the year of the event. The estimated effect is potentially a low estimate of the overall economic impact for several reasons. First, the effects of RMIC are measured on total exports, not total production; estimation of changes to subsets of export flows (for instance excluding commodities and very raw products) would be more closely associated with the supply shock's consequences on domestic production. It is also possible that portions of a negative supply shock are absorbed by the domestic input-output structure and domestic adjustments to demand, which is assumed to be constant in our model. Also, yearly trade flow data are used to keep a large sample of countries and an important disaggregation at the product level. As evidenced in case studies, a supply shock may be relevant for one or two quarters, but disappear for the rest of the year.

To further confirm results, we control the regressions for the share of total imports that are risky and the existing level of trade before the natural disaster. As developed in the paper, importing goods classified as fragile by our methodology has potential adverse effects if and only if there is a disruption of the supply. Regression results confirm this statement: the coefficient associated with imports of fragile products from countries that do not suffer a natural disaster has no statistical significance in the model. Finally, we test the share of total imports in period $t-1$ from a country that suffers a disaster in period $t$; the resultant coefficient is not statistically significant. Column 1 presents regression results for the full sample, while column 2 shows the same estimation applied to a sample which excludes observations corresponding to a country experiencing a disaster in ( $\mathrm{t}-1)$. Table A3 in Annex III confirms the results under an alternative sets of controls.

\footnotetext{
${ }^{30}$ We take care about outliers, by dropping symmetrically one percent of the distribution, as these observations might represent unexpected events and/or mistakes in data that our paper do not aim to model.

${ }^{31}$ Combined effect of the coefficients associated with risky imports from impacted country, risky imports and imports from impacted country from Table 4, column (1).
} 
Table 4. Cross-Country Regressions

\begin{tabular}{lcc}
\hline & $(1)$ & $(2)$ \\
\hline variable of interest & & \\
Risky imports (RM) $(\mathrm{i}, \mathrm{t}-1)$ & -0.216 & -0.208 \\
as a sh. tot. $M$ & $(0.185)$ & $(0.189)$ \\
Imports from an impacted country (MIC) $(\mathrm{i}, \mathrm{t}-\mathrm{-})$ & 0.175 & 0.198 \\
as a sh. tot. $M$ & $(0.139)$ & $(0.146)$ \\
Risky Imports from impacted country (RMIC) $(\mathrm{i}, \mathrm{t}-\mathrm{1})$ & -0.655 & $-0.751^{*}$ \\
as a sh. tot. $M$ & $(0.438)$ & $(0.453)$ \\
controls & & \\
In(REER) (i,t-1) & -0.128 & -0.133 \\
& $(0.114)$ & $(0.119)$ \\
Total exports (i,t-1) & $-0.000^{* *}$ & $-0.000^{*}$ \\
& $(0.000)$ & $(0.000)$ \\
Constant & $0.852^{*}$ & 0.876 \\
& $(0.510)$ & $(0.532)$ \\
& & \\
Observations & 1,725 & 1,625 \\
R-squared & 0.325 & 0.317 \\
Number of countries & 169 & 169 \\
& & \\
Year FE & $\mathrm{Y}$ & $\mathrm{Y}$ \\
Excluding obs. when disaster & $\mathrm{N}$ & $\mathrm{Y}$ \\
Regression type & within-estim. & within-estim. \\
Cluster errors & country-level & country-level \\
\hline
\end{tabular}

Notes: The dependent variable is the country annual export growth in $t$. Estimations report the results of a within-estimator regressions. Robust standard errors in parentheses. $* * * p<0.01, * * p<0.05$, * $p<0.1$.

\section{CONCLUSION AND POTENTIAL APPLICATIONS}

Applying network analysis tools to evaluate and compare the global supply fragility of individual traded goods generates new insight into the supply-side risks of modern international trade. Anecdotal evidence of choke points in the global trade network correspond well with the risky products predicted by network analysis tools. Case study analysis provides some evidence of outsized domestic effects from import supply shocks to risky products (those with the most fragile networks). Using a highly disaggregated international trade database we examine variation in trade networks structure and use these differences in structure and estimates of international substitutability to identify the riskier products globally. We assess the results with a country-level measure of potential supply shock vulnerability based on the composition of countries' individual import basket. This measure can be used to assess potential spillover effects of supply shocks from importing specific goods from specific countries. The methodology additionally can be applied to predict exporters' potential to originate negative spillovers from natural disasters, political instability, and conflicts. 
By exploring the individual characteristics of riskiness of individual goods, in addition to the overall measure, researchers and policymakers can investigate different dimensions of the fragility of an import or set of imports. Likewise, a country-level indicator can be a useful starting point for undertaking nuanced policy-relevant diagnostics and analysis and for identifying specific areas for reform or intervention. Over time, the methodology could be used to evaluate ongoing efforts to improve the resilience of trade to global shocks.

The suggested methodology has a number of potential applications, including (i) as a vigilance tool, (ii) as a tool to evaluate spillovers, and (iii) to assess policies. The country-level share of risky products in import basket can be supplemented by information on main exporters of risky products and the structure of domestic economy to evaluate respective vulnerabilities of countries over time. The data can be used to assess the potential impact of natural disasters or political shocks globally and by country. Maps and network graphs can be helpful in visualizing the spillovers.

Additionally, by increasing the sample to all goods, this methodology can be useful for identifying the potential impact of natural disasters on the supply and prices of consumer goods and raw materials, which is particularly important for low income countries and island countries.

There are several potential extensions to this new research, such as cross-country analysis (for example, the analysis of business cycles and localized supply shocks), analysis of interaction with the global value chain, and analysis of permanent supply shocks (technological progress). The same methodology can be used for the analysis of trade in services, FDI, and other financial instruments. Additionally, it can be a powerful tool for micro level research of firms or industries interconnectedness globally (through, for example, input-output tables).

A number of policy implications emerge from the analysis of risky products and countries vulnerabilities from importing them. As we demonstrate, better monitoring and more-detailed data provide a more robust understanding of the risks inherent in the modern global trade system. Such risks can be foreseen and mitigated by taking network effects of trade into account. For example, as discussed in this paper, shock spillovers can be mitigated by macroeconomic policies that influence the properties of the export-import matrices of individual countries by changing their inand out- degrees, exposure to central players, tendency to cluster, and other network properties. Efforts to diversify suppliers of risky products might be desirable for some countries with highly concentrated imports. Countries may consider insurance mechanisms or policy instruments capable of mitigating domestic risk from trade in risky goods, such as building up strategic physical reserves of certain risky products (at a country or firm level), trade regulations (for example, tax incentives), and trade promotion agencies, each with the intention of mitigating market volatility while ensuring sufficient supply. 


\section{REFERENCES}

Acemoglu, D., Akcigit U., and W. Kerr, 2015, "Networks and the Macroeconomy: An Empirical Exploration," NBER Working Paper Series 21344.

Acemoglu, D., Carvalho, V.M., Ozdaglar, A., and A. Tahbaz-Salehi, 2012, "The network origins of aggregate fluctuations," Econometrica, 80(5):1977-2016.

Andrade da Silva, J., and L. Cernat, 2012, "Coping with loss: the impact of natural disasters on developing countries' trade flows," Directorate General for Trade, European Commission Working Paper No. 1.

Armington, P., 1969, "A Theory of Demand for Products Distinguished by Place of Production," International Monetary Fund Staff Papers, XVI (1969), 159-78.

Aspalter L., 2016, "Estimating Industry-level Armington Elasticities for EMU Countries," Working Paper N217, Department of Economics, Vienna University of Economics and Business.

Baldwin, R., ed. 2009, “The Great Trade Collapse: Causes, Consequences and Prospects,” London: Centre for Economic Policy Research.

Ballester, C., Calvó-Armengol, A., and Y. Zenou, 2006, "Who's who in networks. wanted: the key player," Econometrica, 74(5), pp.1403-1417.

Barrat, A., Barthelemy, M., Pastor-Satorras, R., and A. Vespignani, 2004, "The architecture of complex weighted networks," Proceedings of the National Academy of Sciences of the United States of America, 101(11), pp.3747-3752.

Barrot, J., and J. Sauvagnat, 2014, "Input specificity and the propagation of idiosyncratic shocks in production networks," Working Paper, University of Bocconi.

Bejan, M., 2006, "Trade Openness and Output Volatility," manuscript SSRN

Bergin, P.R., Feenstra, R.C., and G.H. Hanson, 2011, "Volatility due to offshoring: Theory and evidence," Journal of International Economics, 85(2), pp.163-173.

Bems, R., Robert C. J., and K. Yi. 2010, "Demand Spillovers and the Collapse of Trade in the Global Recession,” IMF Economic Review 58 (2): 295-326. , 2013, "The Great Trade Collapse," Annual Review of Economics 5 (1): 375-400.

Besedes, T., and A.P. Murshid, 2014,"The Effects of Airspace Closures on Trade in the Aftermath of Eyjafjallajökull," Georgia Institute of Technology, mimeo.

Blomberg, S.B., and G.D. Hess, 2006, "How Much Does Violence Tax Trade?" The Review of Economics and Statistics, 88(4): 599-612.

Boehm, C., Flaaen A., and N. Pandalai-Nayar, 2014, "Complementarities in Multinational Production and Business Cycle Dynamics," Working paper, University of Michigan.

Bonacich, E., 1972, "A theory of ethnic antagonism: The split labor market," American sociological review, pp.547-559.

Brin and L. Page, 1998, "Computer Networks and ISDN Systems," N30, 107.

Carvalho, V. M., Nirei, M., Saito, Y., and A. Tahbaz-Salehi, 2014, "Supply chain disruptions: evidence from the Great East Japan Earthquake,".

Carvalho, V.M., 2014, "From micro to macro via production networks," The Journal of Economic Perspectives, 28(4), pp.23-47.

Cavallo, E., 2008, "Output Volatility and Openness to Trade: a Reassessment," Journal of LACEA Economia, Latin America and Caribbean Economic Association.

Cavallo, E., Galiani, S., Noy, I. and Pantano, J., 2013. Catastrophic natural disasters and economic growth. Review of Economics and Statistics, 95(5), pp.1549-1561. 
Contreras, M.G.A., and G. Fagiolo, 2014, "Propagation of economic shocks in input-output networks: A cross-country analysis," Physical Review E, 90(6), p.062812.

De Benedictis, L., Nenci, S., Santoni, G., Tajoli, L., and C. Vicarelli, 2014, "Network Analysis of World Trade using the BACI-CEPII dataset," Global Economy Journal, 14(3-4): 287-343.

De la Torre, A., Didier, T., Ize, A., Lederman, D., and S. Schmukler, 2015, Latin America and the Rising South: Changing World, Changing Priorities, Washington, DC: World Bank.

Di Giovanni, J., and A. Levchenko, 2008, "Trade Openness and Volatility," Review of Economics and Statistics, 91(3): 558-585.

Di Giovanni, J., and A. Levchenko, 2010, "Putting the parts together: trade, vertical linkages, and business cycle comovement," American Economic Journal: Macroeconomics 2(2): 95-124.

Djankov, S., Freund, C., and C. Pham, 2010, "Trading on Time," The Review of Economics and Statistics, 92(1): 166-173.

Easterly, W., Islam R., and J. Stiglitz, 2001, "Shaken and Stirred: Explaining Growth Volatility," Annual World Bank Conference on Development Economics, p. 191-212. World Bank, July, 2001.

Escaith, H., Keck A., Nee C., and R. The, 2011, "Japan's earthquake and tsunami: International trade and global supply chain impacts," VoxEU. org, last modified April 28 (2011).

Fagiolo, G., Reyes, J., and S. Schiavo, 2009, "World-trade web: Topological properties, dynamics, and evolution," Physical Review E, 79(3), p.036115.

Fagiolo, G., Reyes, J., and S. Schiavo, 2010, "The evolution of the world trade web: a weightednetwork analysis," Journal of Evolutionary Economics, 20(4), pp.479-514.

Feenstra, R. C., Lipsey R. E., Deng H., Ma A.C., and H. Mo, 2005, "World trade flows: 19622000," National Bureau of Economic Research, No. w11040.

Freund, C., 2009, “The Trade Response to Global Downturns: Historical Evidence," Policy Research Working Paper 5015, World Bank, Washington, DC.

Gabaix, X., 2011, “The granular origins of aggregate fluctuations,” Econometrica, 79(3), pp.733772.

Gassebner, M., Keck A., and R. Teh, 2010. "Shaken, not Stirred: The Impact of Disasters on International Trade," Review of International Economics, 18(2):351-368.

Glick, R., and A.M. Taylor, 2010, “Collateral Damage: Trade Disruption and the Economic Impact of War," The Review of Economics and Statistics, 92(1): 102-127.

Hummels, D., and G. Schaur, 2013, “Time as a Trade Barrier," American Economic Review, 103(7): 2935-59.

IMF, 2013, “Trade interconnectedness: The World with Global Value Chains," Washington, DC: International Monetary Fund.

IMF, 2015, "Review of the Role of Trade in the Work of the Fund," Washington, DC: International Monetary Fund.

Haddad, M., Lim J., and C. Saborowski, 2010, "Trade Openness Reduces Growth Volatility When Countries Are Well Diversified," The World Bank, WPS5222.

Hattori, M., and Y. Suda, 2007, "Developments in a cross-border bank exposure network," In proceedings of a CGFS workshop held at the Bank for International Settlements.

Jackson, M., 2010, Social and Economic Networks, NJ: Princeton University Press

Johnson, R.C., 2014, “Trade in Intermediate Inputs and Business Cycle Comovement," American Economic Journal: Macroeconomics, 6 (4), 2014.

Katz, L., 1953, "A new status index derived from sociometric analysis," Psychometrika 18(1): 3943. 
Kose, A., and K. Yi, 2001, "International Trade and Business Cycles: Is Vertical Specialization the Missing Link?,“'American Economic Review, 91(2):, 371- 375.

Kubelec, C., and F. Sá, 2012, "The Geographical Composition of National External Balance Sheets: 1980-2005," Working paper No. 384. Bank of England.

Long, A.G., 2008 "Bilateral trade in the shadow of armed conflict," International Studies Quarterly, 52(1): 81-101.

Martin, P., Mayer, T., and M. Thoenig, 2008, “Civil Wars and International Trade," Journal of the European Economic Association, 6(2-3): 541-550.

Minoiu, C., and Reyes, J.A., 2013, “A network analysis of global banking: 1978-2010,” Journal of Financial Stability, 9(2), pp.168-184.

Muhammad, A., D'Souza, A., W. Amponsah, and W. W., 2011, "Violence, Political Instability, and International Trade: Evidence from Kenya's Cut Flower Sector," SSRN working paper.

Newman, M.E.J., 2005, "Networks: An Introduction,” UK: Oxford University Press.

Nguyen, D. X., and G. Schaurb, 2012. "Import and Export Linkages Transmit Volatility Across Markets," Working paper, University of Copenhagen.

OECD, 2013, Interconnected Economies: Benefiting from Global Value Chains. Paris: OECD.

Oh, C.H., and R. Reuveny, 2010, "Climatic natural disasters, political risk, and international Trade," Global Environmental Change 20 (2): 243-254.

Sá, F., 2010, "Evidence on financial globalization and crisis: Geographic/bilateral external balance sheets," mimeo.

Saito, M., 2004, "Armington elasticities in intermediate inputs trade: a problem in using multilateral trade data," Canadian Journal of Economics, 37(4): 1097-1117.

Shirotori, M., Tumurchudur, B., and O. Cadot, 2010, "Revealed Factor Intensity Indices at the Product Level," United Nations Conference on Trade and Development Working Paper.

Tabak B., Takami Y., Rocha J., and D. Cajueiro, 2014, "Directed Clustering Coefficient as a Measure of Systemic Risk in Complex Banking Networks," Physica A: Statistical Mechanics and its Applications. Vol. 394: 211-16.

Tanaka, A., 2012, "The effects of FDI on domestic employment and workforce composition. Research Institute of Economy," Trade and Industry (RIETI) Working Paper.

UNCTAD, 2013, World Investment Report: Global Value Chains: Investment and Trade for Development. Geneva: UNCTAD.

Ward, M.D., Ahlquist, J.S., and A. Rozenas, 2013, "Gravity's rainbow: a dynamic latent space model for the world trade network," Network Science,1(01), pp.95-118.

Watts, D.J., and S.H. Strogatz, 1998, "Collective dynamics of 'small-world' networks," Nature, 393(6684): 440-442.

WB, 2015, Global Economic Prospects, Chapter 4, "What Lies Behind the Global Trade Slowdown?", Washington DC, World Bank.

\section{Annex I. Technical Details on the Definition of Components and the Overall Product Fragility Measure}

Our methodology explores the trade network of individual goods. For each network, we use information on which countries export and import the good, and the annual value of exports for 
each resultant pair of countries. Using network analysis terminologies, countries are represented by nodes, and exports will be represented by directed ties linking a pair of nodes. Three network analysis measures are used in the paper:

\section{A. Outdegree Centrality}

Outdegree centrality is a network analysis tool to identify the most influential nodes within a graph. It is defined as the sum of ties that a node directs outward to other nodes as a share of the total number of other nodes. This measure is weighted (the value of the ties is taken into account) and follow the definition of Barrat et al. (2004). The mathematical formulation of the weighted centrality of each country for each product network is:

$$
C_{i}^{\text {out }}=\sum_{j=1}^{n-1} \frac{w_{i j}}{\left\langle w_{j}\right\rangle}
$$

where $C_{i}^{\text {out }}$ is the weighted outdegree centrality of country $i, n$ is the total number of nodes in the network, $w_{i j}$, the value of the exports of country $i$ to country $j$, and $\left\langle w_{j}\right\rangle$ the average value of $j$ 's imports. Formally, $\left\langle w_{j}\right\rangle$ is defined for each product by:

$$
\left\langle w_{j}\right\rangle=\frac{\sum_{i} w_{j i}}{k_{j}}
$$

where $k_{j}$ is the number of nodes $j$ imports from, and $w_{i j}$ the value of the tie between $j$ and $i$. We use the standard deviation of outdegree centrality to measure each product's risk arising from having a few very central exporters. Formally:

$$
\text { Centrality }_{k}=\sqrt{\frac{C_{i k}^{\text {out }}-\overline{C_{k}^{\text {out }}}}{n-1}}
$$

where $\overline{C_{k}^{\text {out }}}$ is the average centrality of countries for product $k$.

\section{B. Tendency to Cluster}

To assess the tendency to cluster of a network of goods, we use two complementary measures:

\section{B.1. Weighted average of local cluster coefficient}

The clustering coefficient measures the degree to which nodes tend to cluster together. The local cluster coefficient in the sense of Watts and Strogatz (1998) quantifies the tendency of the connected nodes of a country to form a clique, i.e. to trade together.

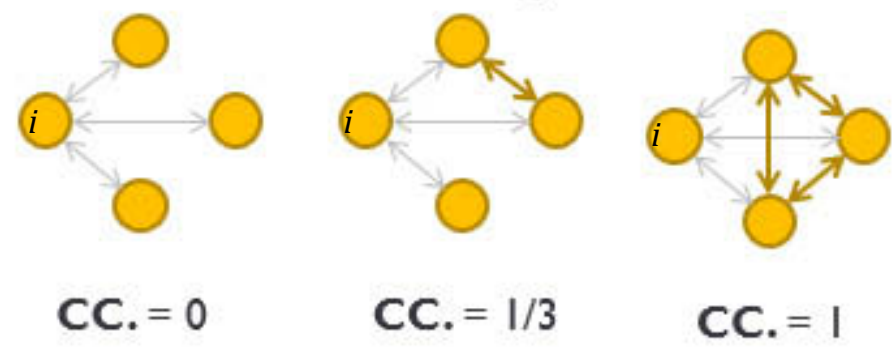


The local clustering coefficient $C C_{i}$ for a node $i$ is given by the proportion of ties between $i$ 's neighbor, divided by the maximal number of possible connections. In the non-weighted version, possible outcomes range from 0 (no connection among the partners of a country) to 1 (all the neighbor countries are connected). We first use the weighted extension proposed by Barrat et al. (2004). A value is assigned to each triplet in the network based on the arithmetic mean. Next, the sum of the value of each closed triplet in the neighbor of each $i$ is calculated and divided by the sum of the value of the triplets.

Formally:

$$
C C_{i}^{w}=\frac{1}{k_{i}\left(k_{i}-1\right)} \sum_{j, k} \frac{1}{\left\langle w_{i}\right\rangle} \frac{w_{i j}+w_{i k}}{2} T_{i j} T_{i k} T_{j k}
$$

Where $k_{i}$ is the number of nodes connected to $i, w_{i j}$ is the value of the tie between $i$ and $j$, and $\left\langle w_{i}\right\rangle$ is the average weight of ties connected with $i$ :

$$
\left\langle w_{i}\right\rangle=\frac{\sum_{j} T_{i j}}{k_{i}}
$$

The weighted local cluster coefficient calculates the contribution of each triangle, weighted by the arithmetic average of the two adjacent ties, to the average weight of all the connections of node $i$.

Note that the direction of the ties is taken into account in this measure.

\section{B.2. Diameter}

The diameter of a network is the length of the shortest path between the most distant nodes, i.e. the length of the longest geodesic path. It calculates the number of steps necessary for a node to reach the furthest node in the network. This measure is directed (the direction of the ties matter) but not weighted.

\section{B.3. Value of the component}

The value of the component of tendency to cluster is then equal to:

$$
\text { Cluster }_{k}=C C_{i}^{w} . \text { Diameter }
$$

\section{International Substitutability}

The last component calculates the dispersion of human capital levels of countries exporting a good. The formulation is the following:

$$
\text { Int }^{\prime} \text { l Substitutability } y_{k}=\sqrt{\frac{L_{i}^{k}-\overline{L_{l}^{k}}}{n-1}}
$$


where $L_{i}^{k}$ is the level of human capital of country $i$ exporter of product $k$. The "wider" the distribution of human capital of exporting countries, the more difficult it will be for a country to find a substitute supplier that corresponds to its standard.

\section{Classifying Overall Product Fragility}

To classify products into groups by riskiness we first normalize the values of the three components described in the Section III.1 by calculating z-scores for each component, year, and product:

$$
z\left(c_{k t}\right)=\frac{c_{k t}-\bar{c}_{t}}{\sigma\left(c_{k t}\right)}
$$

where $z\left(c_{k t}\right)$, the z-score for component $c$, product $k$ and year $t$ is calculated as the raw score for each component, product, and each year, $c_{k t}$, minus the average score for all products in that year, $\bar{c}_{t}$, divided by the standard deviation of the raw score, $\sigma\left(c_{k t}\right)$.

Next, cluster analysis (the k-median procedure) partitions products into mutually exclusive groups, based on their standardized scores for the three components. The algorithm seeks to maximize the variation between clusters and minimize the variation inside. To reach this goal, the algorithm iterates the minimization of the following equation:

$$
\sum_{k} \sum_{c}\left|X_{c k}-\bar{x}_{c}\right|^{2}
$$

where $X_{c k}$ is the value of the component $c$ of product $k$, and $\left|X_{c k}-\bar{x}_{c}\right|$ is the distance between each product and the "center" of the cluster, in this case the median of the current product in the cluster.

After categorizing products, we can track the importers and exporters of risky products by looking at the risky-product share of total imports or exports in a county's trade basket. 


\section{Annex II. Descriptive Statistics}

\section{A. Frequency of Products}

Table A1. Number of Products in Each Category Over Time

\begin{tabular}{c||cccc||c} 
& Group 1 & Group 2 & Group 3 & Group 4 & $\begin{array}{c}\text { Non- } \\
\text { classified }\end{array}$ \\
\hline \hline 2003 & 887 & 839 & 1146 & 689 & 0 \\
2004 & 962 & 846 & 1091 & 656 & 15 \\
2005 & 878 & 783 & 1247 & 654 & 11 \\
2006 & 969 & 800 & 1110 & 672 & 24 \\
2007 & 1029 & 735 & 1112 & 679 & 21 \\
2008 & 1036 & 728 & 1119 & 672 & 21 \\
2009 & 838 & 848 & 1129 & 700 & 61 \\
2010 & 981 & 766 & 1112 & 657 & 60 \\
2011 & 983 & 733 & 1109 & 667 & 84 \\
2012 & 1043 & 818 & 1073 & 570 & 74 \\
2013 & 1079 & 711 & 1094 & 615 & 79 \\
2014 & 1040 & 694 & 1126 & 640 & 78
\end{tabular}

Notes: The table summarizes the frequency of products over time in the four risk groups, with group 4 being the riskiest. On average across years, 655 products are categorized in the riskier group (Group 4). Products which the algorithm fails to associate to a group are shown in the "non-classified" column. 


\section{B. List of Risky Products}

Table A2. 100 Most Traded Risky Products During 2003-2014

\begin{tabular}{|c|c|c|c|}
\hline & HS2002_6d & Product Description & $\begin{array}{c}\text { Share } \\
\text { Value of } \\
\text { Imports }\end{array}$ \\
\hline 1 & 847170 & Storage units (of auto. data processing machines) & $0.964 \%$ \\
\hline 2 & 880330 & Parts of aeroplanes/helicopters, other than propellers, rotors, under-carri ... & $0.761 \%$ \\
\hline 3 & 870829 & Parts $\&$ accessories of bodies (incl. cabs) of the motor vehicles of $87.01-8 \ldots$ & $0.717 \%$ \\
\hline 4 & 300210 & Antisera $\&$ oth. blood fractions \& modified immunological prods., whether or ... & $0.671 \%$ \\
\hline 5 & 870421 & Motor vehicles for the tpt. of gds. (excl. of 8704.10$)$, with C-I int. comb. ... & $0.573 \%$ \\
\hline 6 & 848180 & Taps, cocks, valves \& sim. appls. for pipes/boiler shells/tanks/vats or the ... & $0.537 \%$ \\
\hline 7 & 850440 & Static converters & $0.523 \%$ \\
\hline 8 & 841191 & Parts of the turbo-jets/turbo-propellers of $8411.11-8411.22$ & $0.470 \%$ \\
\hline 9 & 401110 & New pneumatic tyres, of rubber, of a kind used on motor cars (incl. station ... & $0.463 \%$ \\
\hline 10 & 901890 & Instruments \& appls. used in medical/surgical/veterinary sciences, incl. ot ... & $0.455 \%$ \\
\hline 11 & 853400 & Printed circuits & $0.445 \%$ \\
\hline 12 & 854140 & Photosensitive semiconductor devices, incl. photovoltaic cells whether or $\mathrm{n}$... & $0.443 \%$ \\
\hline 13 & 732690 & Articles of iron/steel, n.e.s. & $0.423 \%$ \\
\hline 14 & 853710 & Boards, panels, consoles, desks, cabinets $\&$ oth. bases, equipped with $2 /$ mor $\ldots$ & $0.413 \%$ \\
\hline 15 & 840734 & Spark ignition recip. piston engines of a kind used for the propulsion of $v \ldots$ & $0.399 \%$ \\
\hline 16 & 853690 & Electrical app. for switching/protecting electrical circuits,/for making co ... & $0.399 \%$ \\
\hline 17 & 840820 & Compression-ignition int. comb. piston engines (diesel/semi-diesel engines) ... & $0.392 \%$ \\
\hline 18 & 840999 & Parts suit. for use solely/princ. with the engines of $84.07 / 84.08$ (excl. of ... & $0.391 \%$ \\
\hline 19 & 840991 & Parts suit. for use solely/princ. with spark-ignition int. comb. piston eng ... & $0.388 \%$ \\
\hline 20 & 870431 & Motor vehicles for the tpt. of gds. (excl. of 8704.10 ), with spark-ignition ... & $0.349 \%$ \\
\hline 21 & 854430 & Ignition wiring sets $\&$ oth. wiring sets of a kind used in vehicles/aircraft ... & $0.348 \%$ \\
\hline 22 & 730890 & Structures...\& parts of structures...of iron/steel (excl. of 7308.10-7308.4 ... & $0.340 \%$ \\
\hline 23 & 870120 & Road tractors for semi-trailers (excl. of 87.09) & $0.330 \%$ \\
\hline 24 & 390110 & Polyethylene having a sp.gr. of $<0.94$, in primary forms & $0.323 \%$ \\
\hline 25 & 853890 & Parts suit. for use solely/princ. with the app. of $85.35 / 85.36 / 85.37$ (excl. ... & $0.322 \%$ \\
\hline 26 & 390120 & Polyethylene having a sp.gr. of $0.94 /$ more, in primary forms & $0.311 \%$ \\
\hline 27 & 870839 & Brakes \& servo-brakes \& parts thereof (excl. mounted brake linings) for the ... & $0.311 \%$ \\
\hline 28 & 940190 & Parts of the seats of 94.01 & $0.310 \%$ \\
\hline 29 & 843149 & Parts suit. for use solely/princ. with the mach. of $84.26 / 84.29 / 84.30$ (excl ... & $0.301 \%$ \\
\hline 30 & 390210 & Polypropylene, in primary forms & $0.290 \%$ \\
\hline 31 & 401120 & New pneumatic tyres, of rubber, of a kind used on buses/lorries & $0.277 \%$ \\
\hline 32 & 854459 & Electric conductors (excl. of $8544.11-8544.30)$, for a voltage $>80 \mathrm{~V}$ but not ... & $0.273 \%$ \\
\hline 33 & 842952 & Self-propelled mech. shovels \& excavators with a 360 revolving superstruct ... & $0.265 \%$ \\
\hline 34 & 844359 & Printing mach. n.e.s. in 84.43 & $0.261 \%$ \\
\hline 35 & 870422 & Motor vehicles for the tpt. of gds. (excl. of 8704.10$)$, with C-I int. comb. ... & $0.256 \%$ \\
\hline 36 & 903289 & Automatic regulating/controlling instr. \& app., n.e.s. in 90.32 & $0.245 \%$ \\
\hline 37 & 870190 & Tractors n.e.s. in 87.01 (excl. of 87.09) & $0.242 \%$ \\
\hline 38 & 760612 & Plates, sheets \& strip, rect. (incl. square), of a thkns. $>0.2 \mathrm{~mm}$, of alumin ... & $0.242 \%$ \\
\hline 39 & 841199 & Parts of the oth. gas turbines of $8411.81 \& 8411.82$ & $0.240 \%$ \\
\hline 40 & 841480 & Air pumps, air/oth. gas compressors \& fans (excl. of 8414.10-8414.59); vent ... & $0.234 \%$ \\
\hline
\end{tabular}




\begin{tabular}{|c|c|c|c|}
\hline 41 & 901839 & Catheters, cannulae and the like & $0.229 \%$ \\
\hline 42 & 854441 & Electric conductors (excl. of 8544.11-8544.30), for a voltage not $>80 \mathrm{~V}$, fit ... & $0.228 \%$ \\
\hline 43 & 151190 & Palm oil, other than crude, \& fractions thereof, whether or not ref. but $n \ldots$ & $0.227 \%$ \\
\hline 44 & 850300 & Parts suit. for use solely/princ. with the machines of $85.01 / 85.02$ & $0.220 \%$ \\
\hline 45 & 90111 & Coffee, not roasted, not decaffeinated & $0.220 \%$ \\
\hline 46 & 903180 & Measuring/checking instr., app.\& machines, n.e.s. in Ch. 90 & $0.217 \%$ \\
\hline 47 & 853650 & Switches other than isolating switches \& make-\&-break switches, for a volta ... & $0.215 \%$ \\
\hline 48 & 870423 & Motor vehicles for the tpt. of gds. (excl. of 8704.10), with C-I int. comb.... & $0.208 \%$ \\
\hline 49 & 852190 & Video recording/repr. app. other than magnetic tape-type, whether or not in ... & $0.201 \%$ \\
\hline 50 & 300220 & Vaccines for human medicine & $0.201 \%$ \\
\hline 51 & 870870 & Road wheels \& parts \& accessories thereof for the motor vehicles of $87.01-8 \ldots$ & $0.195 \%$ \\
\hline 52 & 843143 & Parts suit. for use solely/princ. with the boring/sinking mach. of $8430.41 / \ldots$ & $0.192 \%$ \\
\hline 53 & 731815 & Screws \& bolts (excl. of 7318.11-7318.14), whether or not with their nuts/w ... & $0.189 \%$ \\
\hline 54 & 842139 & Filtering/purifying mach. \& app. for gases, other than intake air filters $f$... & $0.185 \%$ \\
\hline 55 & 848340 & Gears\&gearing(excl. toothed wheels, chain sprockets \&oth. transmission eleme ... & $0.185 \%$ \\
\hline 56 & 841391 & Parts of the pumps of $8413.11-8413.81$ & $0.183 \%$ \\
\hline 57 & 848190 & Parts of the appls. of 84.81 & $0.182 \%$ \\
\hline 58 & 841490 & Parts of the pumps, compressors, fans \& recycling hoods of $8414.10-8414.20$ & $0.180 \%$ \\
\hline 59 & 850780 & Electric accumulators, incl. separators therefor, whether or not rect. (inc ... & $0.165 \%$ \\
\hline 60 & 841430 & Compressors of a kind used in refrigerating equip. & $0.163 \%$ \\
\hline 61 & 848210 & Ball bearings & $0.160 \%$ \\
\hline 62 & 841590 & Parts of the air-conditioning machines of $8415.10-8415.83$ & $0.160 \%$ \\
\hline 63 & 870210 & Motor vehicles for the tpt. of 10/more persons incl. the driver, with C-I i ... & $0.159 \%$ \\
\hline 64 & 330210 & Mixtures of odoriferous subs. \& mixts. (incl. alcoholic solutions) with a b ... & $0.157 \%$ \\
\hline 65 & 761699 & Articles of aluminium n.e.s. in Ch.76 & $0.157 \%$ \\
\hline 66 & 853669 & Plugs \& sockets for a voltage not $>1000 \mathrm{~V}$ & $0.156 \%$ \\
\hline 67 & 392190 & Plates, sheets, film, foil \& strip (excl. cellular), of plastics, n.e.s. in ... & $0.156 \%$ \\
\hline 68 & 854129 & Transistors (excl. photosensitive transistors), other than those with a dis ... & $0.156 \%$ \\
\hline 69 & 852691 & Radio navigational aid app. & $0.153 \%$ \\
\hline 70 & 940320 & Metal furniture (excl. of $94.01 \& 94.02)$ & $0.151 \%$ \\
\hline 71 & 390690 & Acrylic polymers other than poly(methyl methacrylate), in primary forms & $0.150 \%$ \\
\hline 72 & 850110 & Electric motors of an output not $>37.5 \mathrm{~W}$ & $0.150 \%$ \\
\hline 73 & 840890 & Internal combustion piston engines (diesel/semi-diesel engines) (excl. of 8 ... & $0.148 \%$ \\
\hline 74 & 841370 & Centrifugal pumps (excl. of 8413.11-8413.40) & $0.146 \%$ \\
\hline 75 & 690890 & Glazed ceramic flags \& paving/hearth/wall tiles (excl. of 6908.10); glazed ... & $0.144 \%$ \\
\hline 76 & 940510 & Chandeliers \& oth. elec. ceiling/wall lighting fittings (excl. those of a k ... & $0.144 \%$ \\
\hline 77 & 842951 & Self-propelled front-end shovel loaders & $0.143 \%$ \\
\hline 78 & 950490 & Articles for funfair/table/parlour games (excl. playing cards), incl. pinta ... & $0.142 \%$ \\
\hline 79 & 230990 & Preparations of a kind used in animal feeding other than dog/cat food put $u$... & $0.138 \%$ \\
\hline 80 & 851220 & Lighting/visual signalling equip. of a kind used for cycles (excl. bicycles ... & $0.137 \%$ \\
\hline
\end{tabular}




\begin{tabular}{|c|c|c|c|}
\hline 81 & 940540 & Electric lamps \& lighting fittings, n.e.s. in 94.05 & $0.137 \%$ \\
\hline 82 & 841330 & Fuel/lubricating/cooling medium pumps for int. comb. piston engines & $0.137 \%$ \\
\hline 83 & 391990 & Self-adhesive plates, sheets, film, foil, tape, strip \& oth. flat shapes, o ... & $0.135 \%$ \\
\hline 84 & 842199 & Parts of the filtering/purifying mach. \& app. of 84.21 (excl. of centrifuge ... & $0.134 \%$ \\
\hline 85 & 401699 & Articles of vulcanised rubber other than hard rubber, n.e.s. in Ch.40 & $0.131 \%$ \\
\hline 86 & 390720 & Polyethers other than polyacetals, in primary forms & $0.129 \%$ \\
\hline 87 & 848310 & Transmission shafts (incl. cam shafts \& crank shafts) \& cranks & $0.122 \%$ \\
\hline 88 & 392310 & Boxes, cases, crates \& sim. arts., of plastics & $0.121 \%$ \\
\hline 89 & 401693 & Gaskets, washers \& oth. seals of vulcanised rubber other than hard rubber & $0.120 \%$ \\
\hline 90 & 854110 & Diodes (excl. photosensitive/light emitting diodes) & $0.118 \%$ \\
\hline 91 & 392321 & Sacks \& bags (incl. cones), of polymers of ethylene & $0.116 \%$ \\
\hline 92 & 902780 & Instruments \& app. for physical/chem. analysis, n.e.s. in 90.27 & $0.116 \%$ \\
\hline 93 & 760429 & Bars, rods \& profiles (excl. hollow profiles) of aluminium alloys & $0.115 \%$ \\
\hline 94 & 850490 & Parts of the machines of 85.04 & $0.115 \%$ \\
\hline 95 & 240120 & Tobacco, partly/wholly stemmed/stripped & $0.113 \%$ \\
\hline 96 & 848390 & Toothed wheels, chain sprockets \& oth. transmission elements presented sep.... & $0.111 \%$ \\
\hline 97 & 841950 & Heat exchange units, whether or not electrically heated & $0.111 \%$ \\
\hline 98 & 902790 & Microtomes; parts \& accessories of instr. \& app. of 90.27 & $0.109 \%$ \\
\hline 99 & 841459 & Fans, other than table/floor/wall/window/ceiling/roof fans, with a self-con ... & $0.103 \%$ \\
\hline 100 & 901819 & Electro-diagnostic app. used in medical/surgical/dental/veterinary sciences ... & $0.103 \%$ \\
\hline
\end{tabular}

Notes: Products are considered as risky if they constantly are classified in Group 4 during 2003-2014.

Products are sorted by their relative importance in the world trade between 2003-2014. 


\section{Annex III. Fragility Maps Over Time}

\section{Share of Total Imports of Fragile Products 2003}

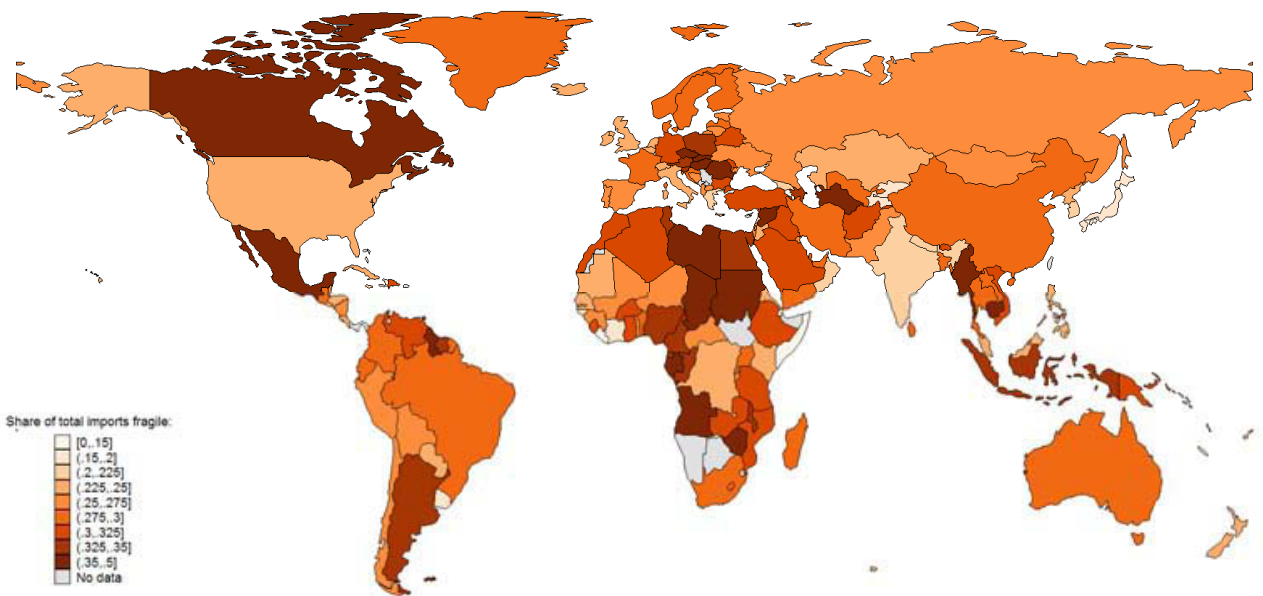

2009

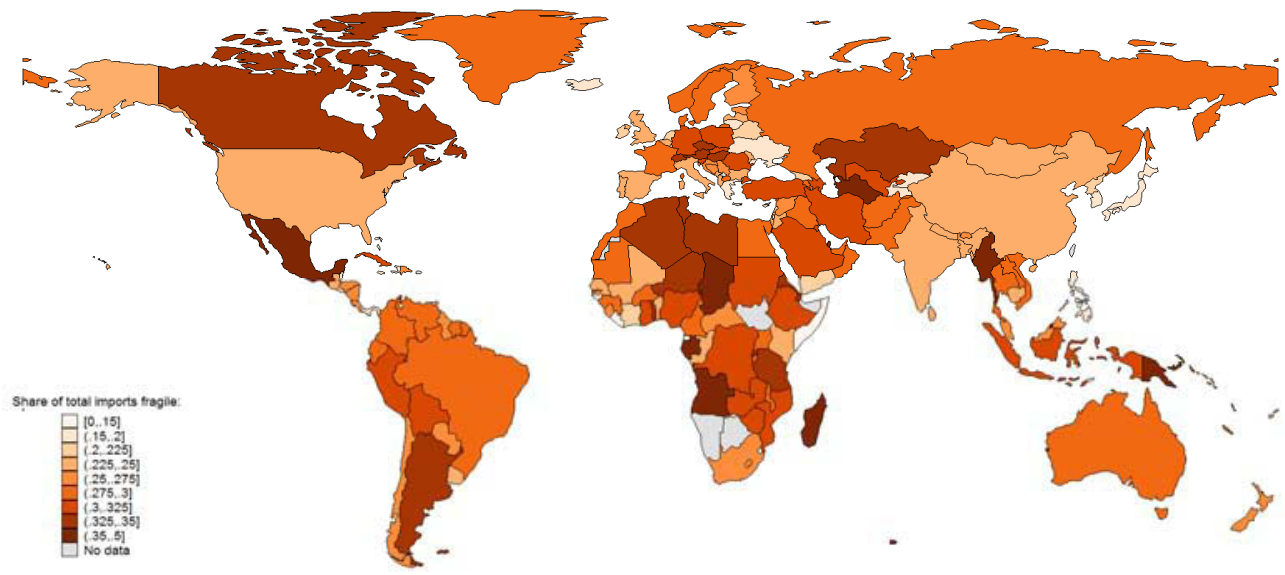

2013

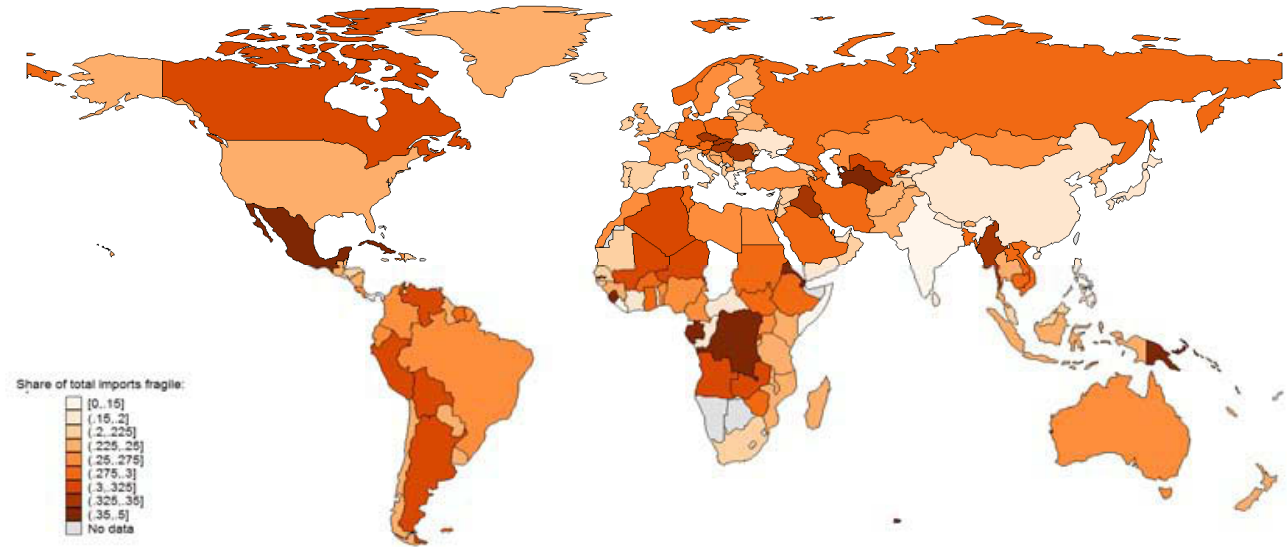

Notes: Over time, the share of imports of risky products have increased in Latin America, Russia and Australia, and decreased in Europe and East Asia. 


\section{Share of World Exports of Fragile Products}

2003

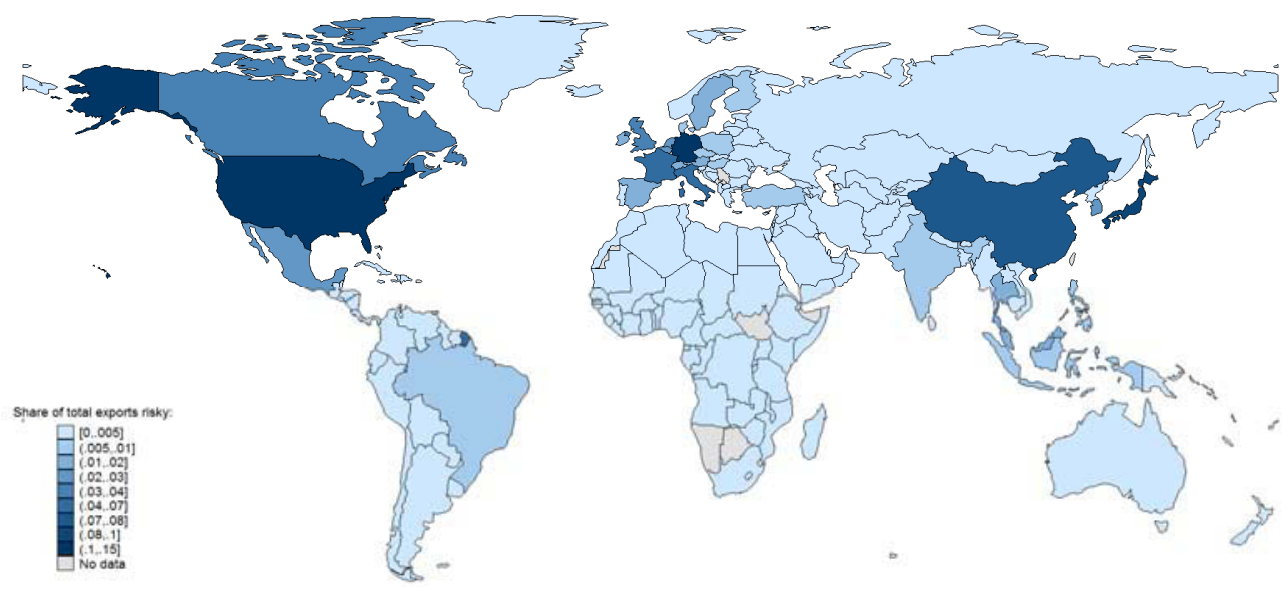

2009

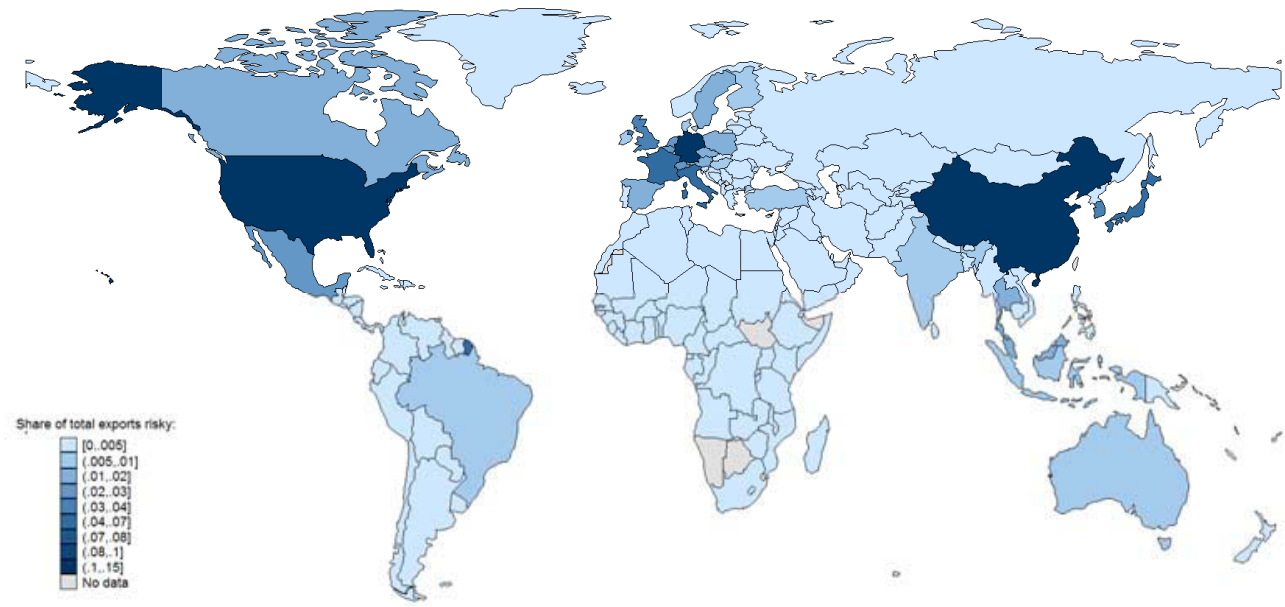

2013

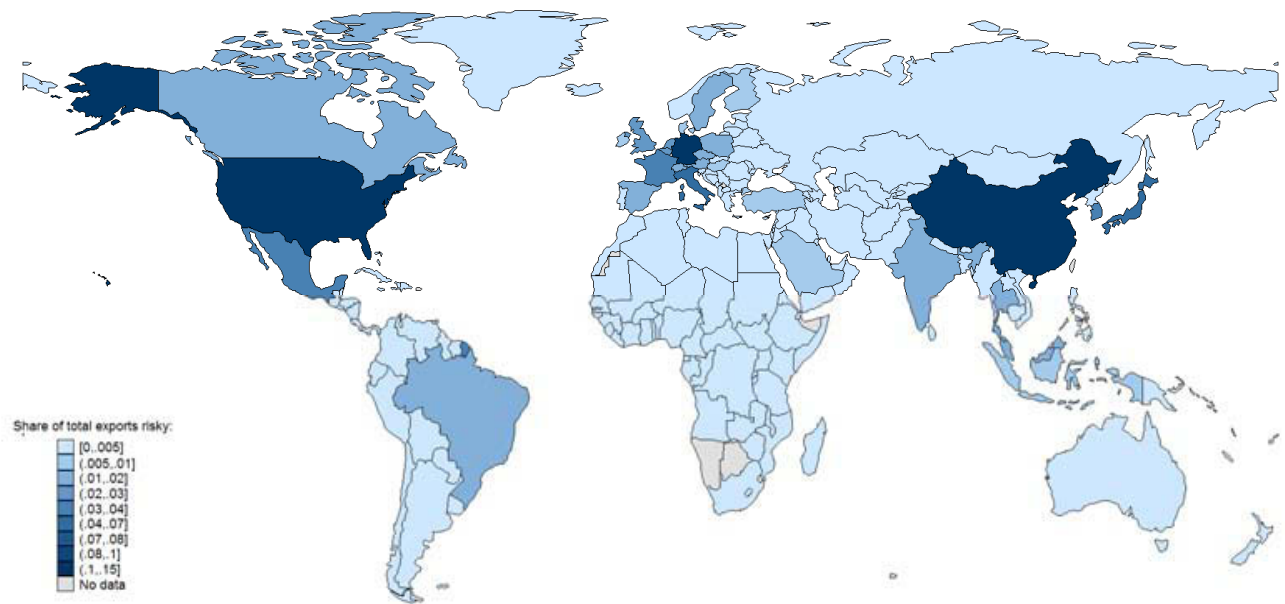

Notes: Regions exporting risky goods are stable over time, and have become more concentrated in recent years. 


\begin{tabular}{|c|c|c|c|c|c|c|c|c|c|c|}
\hline & (1) & (2) & (3) & (4) & (5) & (6) & (7) & (8) & (9) & (10) \\
\hline \multicolumn{11}{|l|}{ variable of interest } \\
\hline Risky imports (RM) (i,t-1) & -0.205 & -0.195 & -0.183 & -0.176 & -0.224 & -0.217 & -0.204 & -0.199 & -0.287 & -0.282 \\
\hline as a sh. tot. $M$ & (0.185) & (0.189) & $(0.188)$ & (0.192) & $(0.184)$ & $(0.188)$ & $(0.185)$ & $(0.189)$ & $(0.175)$ & $(0.178)$ \\
\hline Imports from an impacted country (MIC) (i,t-1) & $0.265^{*}$ & $0.295 *$ & $0.244^{*}$ & $0.273^{*}$ & 0.183 & 0.206 & 0.174 & 0.196 & 0.164 & 0.187 \\
\hline as a sh. tot. $M$ & (0.149) & $(0.158)$ & $(0.146)$ & $(0.154)$ & $(0.141)$ & $(0.147)$ & $(0.139)$ & $(0.146)$ & $(0.138)$ & $(0.145)$ \\
\hline Risky Imports from impacted country $(\mathrm{RMIC})_{(\mathrm{i}, \mathrm{t}-1)}$ & $-0.914^{*}$ & $-1.019 * *$ & $-0.883^{*}$ & $-0.990 * *$ & -0.643 & -0.731 & -0.649 & -0.741 & -0.644 & -0.743 \\
\hline as a sh. tot. $M$ & $(0.476)$ & $(0.495)$ & $(0.462)$ & $(0.481)$ & $(0.444)$ & $(0.459)$ & $(0.438)$ & $(0.453)$ & $(0.439)$ & $(0.454)$ \\
\hline \multicolumn{11}{|l|}{ controls } \\
\hline \multirow[t]{2}{*}{$\ln ($ REER) $(i, t-1)$} & -0.123 & -0.131 & -0.140 & -0.146 & -0.114 & -0.121 & -0.130 & -0.136 & -0.120 & -0.124 \\
\hline & $(0.122)$ & $(0.128)$ & $(0.117)$ & $(0.122)$ & $(0.119)$ & $(0.125)$ & $(0.114)$ & $(0.119)$ & $(0.113)$ & $(0.118)$ \\
\hline \multirow[t]{2}{*}{ Volume of exports growth $(i, t-1)$} & -0.017 & -0.016 & -0.013 & -0.012 & & & & & & \\
\hline & $(0.012)$ & $(0.011)$ & $(0.012)$ & $(0.011)$ & & & & & & \\
\hline \multirow[t]{2}{*}{ Imports as a share of GDP $(\mathrm{i}, \mathrm{t}-1)$} & 0.151 & 0.143 & & & 0.131 & 0.122 & & & & \\
\hline & $(0.133)$ & $(0.141)$ & & & $(0.127)$ & $(0.134)$ & & & & \\
\hline \multirow[t]{2}{*}{ Exports as a share of $\operatorname{GDP}_{(\mathrm{i}, \mathrm{t}-1)}$} & & & & & & & & & $-0.000^{* *}$ & $-0.000^{* *}$ \\
\hline & & & & & & & & & $(0.000)$ & $(0.000)$ \\
\hline \multirow[t]{2}{*}{ Constant } & 0.768 & 0.802 & $0.891^{*}$ & $0.919^{*}$ & 0.737 & 0.769 & $0.851^{*}$ & 0.876 & 0.834 & 0.855 \\
\hline & $(0.564)$ & $(0.596)$ & $(0.521)$ & $(0.544)$ & $(0.551)$ & $(0.581)$ & $(0.511)$ & $(0.533)$ & $(0.507)$ & $(0.528)$ \\
\hline Observations & 1,688 & 1,588 & 1,701 & 1,601 & 1,712 & 1,612 & 1,725 & 1,625 & 1,718 & 1,619 \\
\hline R-squared & 0.335 & 0.326 & 0.333 & 0.324 & 0.325 & 0.316 & 0.323 & 0.315 & 0.326 & 0.317 \\
\hline Number of countries & 169 & 169 & 169 & 169 & 169 & 169 & 169 & 169 & 169 & 169 \\
\hline Year FE & Y & Y & Y & Y & Y & Y & Y & Y & Y & Y \\
\hline Excluding obs. when disaster & $\mathrm{N}$ & Y & $\mathrm{N}$ & $\mathrm{Y}$ & $\mathrm{N}$ & $\mathrm{Y}$ & $\mathrm{N}$ & $\mathrm{Y}$ & $\mathrm{N}$ & $\mathrm{Y}$ \\
\hline Regression type & \multirow{2}{*}{\multicolumn{10}{|c|}{$\begin{array}{l}\text { within-estim. within-estim. within-estim. within-estim. within-estim. within-estim. within-estim. within-estim. within-estim. within-estim } \\
\text { country-level country-level country-level country-level country-level country-level country-level country-level country-level country-level }\end{array}$}} \\
\hline Cluster errors & & & & & & & & & & \\
\hline
\end{tabular}

Notes: The dependent variable is the country's annual export growth in t. Estimations report the results of within-estimators regression. Robust standard errors are in parentheses, with significance levels marked as follows: *** $p<0.01, * * p<0.05, * p<0.1$. Note that the coefficient associated with risky imports from impacted countries in column (6) to (12) are statistically significant at 15\%. This table confirms the main results found in Table 4, using alternative sets of control variable. From column (1) to (10), the coefficient associated to the share of total imports that are risky and importing from a country suffering a disaster is consistently negative and always statistically significant with a 15\% confidence interval. It is also remarkable that the share of total imports that are risky is never statistically significant, while the total imports from an impacted country is in general not statistically significant, and when it is (from column 1 to 4) the coefficient is inferior clearly inferior to the share of risky imports from impacted country. Also, all the regressions control for the REER. The coefficient associated is consistently negative. Odd columns include the full sample of observations while even columns exclude observations of countries suffering a shock. Columns (1) and (2) control the basic regression for the volume of export growth one year before and the level of imports a share of GDP. The coefficient associated with the volume of exports growth is negative while the coefficient associated with the ratio of imports to GDP is positive. The signs of these coefficient are confirmed in columns (3) to (6). None of them are statistically significant. Column (7) and (8) presents results associated to the control of the regressions only by the REER. Results hold. Finally, columns (9) and (10) control for REER and the ratio of exports to GDP. The hiaher the relative importance of exports in the economv. the worse the impact on exports 